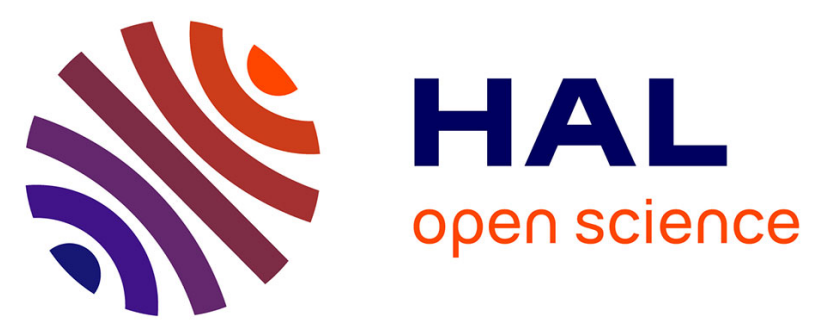

\title{
Assessing non-chemical weeding strategies through mechanistic modelling of blackgrass (Alopecurus myosuroides Huds.) dynamics
}

Nathalie Colbach, D.A.G. Kurstjens, Nicolas Munier-Jolain, A. Dalbiès, Thierry Doré

\section{To cite this version:}

Nathalie Colbach, D.A.G. Kurstjens, Nicolas Munier-Jolain, A. Dalbiès, Thierry Doré. Assessing non-chemical weeding strategies through mechanistic modelling of blackgrass (Alopecurus myosuroides Huds.) dynamics. European Journal of Agronomy, 2010, 32 (3), pp.205-218. 10.1016/j.eja.2009.11.005 . hal-01173174

\section{HAL Id: hal-01173174 \\ https://hal.science/hal-01173174}

Submitted on 14 Aug 2019

HAL is a multi-disciplinary open access archive for the deposit and dissemination of scientific research documents, whether they are published or not. The documents may come from teaching and research institutions in France or abroad, or from public or private research centers.
L'archive ouverte pluridisciplinaire HAL, est destinée au dépôt et à la diffusion de documents scientifiques de niveau recherche, publiés ou non, émanant des établissements d'enseignement et de recherche français ou étrangers, des laboratoires publics ou privés. 


\title{
1 Assessing non-chemical weeding strategies through mechanistic modelling of blackgrass (Alopecurus myosuroides Huds.) dynamics
}

\author{
N. Colbach ${ }^{1,2,3}$, D.A.G. Kurstjens ${ }^{4}$, N.M. Munier-Jolain ${ }^{1,2,3}$, A. Dalbiès ${ }^{5,6}$, T. Doré5,6
}

5

${ }^{1}$ INRA, UMR 1210 Biologie et Gestion des Adventices, F-21000 Dijon, France

${ }^{2}$ AgroSup Dijon, UMR 1210 Biologie et Gestion des Adventices, F-21000 Dijon, France

${ }^{3}$ Université de Bourgogne, UMR 1210 Biologie et Gestion des Adventices, F-21000 Dijon, France

${ }^{4}$ Wageningen University, Farm Technology Group, P.O. box 17, 6700 AA Wageningen, The Netherlands. Present address: Hanze University, School of Engineering, Zernikeplein 11, 9747 AS Groningen, The Netherlands

${ }^{5}$ INRA, UMR 211 INRA/AgroParisTech, BP 01, F-78850 Thiverval-Grignon

${ }^{6}$ AgroParisTech, UMR 211 INRA/AgroParisTech, BP 01, F-78850 Thiverval-Grignon

Address for correspondence:

Nathalie Colbach, INRA, UMR 1210 Biologie et Gestion des Adventices, BP 86510, 17 rue Sully F21065 Dijon Cedex, France (Nathalie.Colbach@dijon.inra.fr)

Tel. +33-3 80693033

Fax: +33-3 80693262

\section{Abstract}

Because of environmental and health safety issues, it is necessary to develop strategies that do not rely on herbicides to manage weeds. Introducing temporary grassland into annual crop rotations and mechanical weeding are the two main features that are frequently used in integrated and organic cropping systems for this purpose. To evaluate the contribution of these two factors in interaction with other cropping system components and environmental conditions, the present study updated an existing biophyiscal model (i.e. ALOMYSYS) that quantifies the effects of cropping system on weed dynamics. Based on previous experiments, new submodels were built to describe the effects on plant survival and growth reduction of mechanical weeding resulting from weed seedling uprooting and covering by soil, and those of grassland mowing resulting from tiller destruction. Additional modifications described the effect of the multi-year crop canopy of grassland on weed survival, growth, development and seed return to the soil. The improved model was used to evaluate the weed dynamics over 27 years in the conventional herbicide-based cropping system most frequently observed in farm surveys (i.e. oilseed rape/winter wheat/winter barley rotation with superficial tillage) and then 
to test prospective non-chemical scenarios. Preliminary simulations tested a large range of mechanical weeding and mowing strategies, varying operation frequencies, dates and, in the case of mechanical weeding, characteristics (i.e. tool, working depth, tractor speed). For mechanical weeding soon after sowing, harrowing was better than hoeing for controlling weed seed production. The later the operation, the more efficient the hoeing and the less efficient the harrowing. Tractor speed had little influence. Increasing the tilling depth increased plant mortality but increased weed seed production because of additional seed germination triggering by the weeding tool. Decreasing the interrow width for hoeing was nefarious for weed control. The best combinations were triple hoeing in oilseed rape and sextuple harrowing in cereals. The best mowing strategy was mowing thrice, every 4-6 weeks, starting in mid-May. The best individual options were combined, simulated over 27 years and compared to the herbicide-based reference system. If herbicide applications were replaced solely by mechanical weeding, blackgrass infestation could not be satisfactorily controlled. If a three-year lucerne was introduced into the rotation, weed infestations were divided by ten. Replacing chisel by mouldboard ploughing before winter wheat reduced weed infestations at short, medium and long-term to a level comparable to the herbicide-based reference system.

Keywords. cropping system, weed dynamics, model, mechanical weeding, grassland, integrated crop protection

\section{Introduction}

Until a few years ago, weed management in Western Europe relied almost exclusively on herbicide applications. However, herbicide-resistant weeds are increasingly reported because of the repetitive use of similar active ingredients (Moss, 1987; Darmency and Gasquez, 1990; Gressel and Segel, 1990; Hole and Powles, 1997). In addition, herbicides are those pesticides that are most frequently identified in ground and surface water (IFEN, 2007). It therefore becomes necessary to develop other strategies for managing weeds. The situation is changing rapidly, with the extension of integrated pest management and organic agriculture. Consequently, there is an increasing amount of references for non-chemical weed management, both in organic and conventional farming. Syntheses have been published recently (Chicouene, 2007; Van Der Weide et al., 2008) on mechanical weeding (i.e. tilling the soil during the cropping season to destroy weeds as opposed to tillage during summer fallow), on which non-chemical weed management often relies in annual crops. Multi-year crops such as temporary grassland or lucerne are already a frequent feature in organic rotations and are requested to increase in conventional rotations for ecological purposes. In these crops, mechanical weeding is mostly carried out during the first crop year, and weeds are mainly controlled with frequent mowing operations. For the latter, scientific knowledge is scarce.

It is now well recognized that models that quantify the effects of weed management techniques on weeds dynamics are valuable tools to design weed management strategies (Aubertot et al.,; Rossing et 

al., 1997). To understand and predict the variability in effects observed for given techniques and to use these models in a large range of conditions without reparametrising, mechanistic approaches where life-cycles are split into sub-processes depending on biological and physical effects of cropping systems, in interaction with the biological (e.g. weed stage) and physical conditions (e.g. soil structure) are necessary (Colbach and Debaeke, 1998; Colbach et al., 2005). Though numerous demographic weed models have been developed in the past for cropping system effects (see reviews by Doyle, 1997; Colbach and Debaeke, 1998; Holst et al., 2007), only a single available one answers to the previous requirements to date. The ALOMYSYS model (Colbach et al., 2006a; 2006b; Colbach et al., 2007) was developed for Alopecurus myosuroides Huds. (blackgrass), an annual grass-weed frequently found in autumn-sown crop rotations of Atlantic European countries (Van Himme and Bulcke, 1975) and increasingly tolerant to various herbicides (Moss, 1987; Gasquez, 1996).

However, ALOMYSYS has not considered features such as mechanical weeding, mowing or multi-year crops. Consequently, the aim of the present paper was to integrate these techniques into ALOMYSYS. The structure of ALOMYSYs based on sub-models detailing the various life-cycle processes makes the addition of these techniques possible without modifying the core model. To evaluate the efficiency of the innovative techniques for managing weeds, a simulation methodology was proposed, combining farm surveys with simulations of individual techniques and comprehensive cropping systems, to identify efficient weed control strategies for farmers in a case study.

\section{Material and methods}

\subsection{Model structure}

\subsubsection{The main features of ALOMYSYS}

The structure of ALOMYSYS is described in detail by Colbach et al. (2006a; 2006b; 2007). Only the main aspects are described here.

The input variables of ALOMYSYS consist of:

- the above-ground climate: temperature and rainfall for each simulated day;

- the soil climate, either measured in the field or simulated with existing models such as STICS (Brisson et al., 1998a): temperature, soil moisture and water potential for each day and for each of the 30 soil layers ranging from 0 to $30 \mathrm{~cm}$;

- a description of the simulated location: soil texture and depth, initial soil structure (fragmented, intermediate, compacted) and initial soil moisture (dry, intermediate, moist)

- the initial seed bank: seed density and characteristics (age, weight, conditions of seed production) for each soil layer and the two seed age classes (freshly produced, older than one year); 
- the cropping system during the whole simulated period, comprising the crop sequence including set-aside and cover crops, the date of all operations (tillage, sowing, herbicides, harvest) and their characteristics, i.e. tool, working depth etc. for tillage, active ingredient, rate and conditions (good, intermediate, bad) for herbicides, seed density for sowing, and total applied rate for nitrogen fertilization.

These input variables influence the annual life-cycle of blackgrass (Table 1), in interaction with blackgrass stages (e.g. mortality after herbicide application depends on blackgrass stage and density), crop stages (e.g. seedling survival after emergence depends on its emergence date relative to the crop emergence date) and environmental conditions (e.g. pre-emergent seedling mortality increases with the size and compaction of soil clods as well as soil dryness). All life-stages are described in output files, but the main output variables comprise daily emerging seedlings, total density of mature weeds at crop harvest, their seed production, and the seed bank consisting of viable seeds both on surface and

buried at different depths in the soil.

118 In the subsequent sections, the sub-models added for describing multi-year grassland, mowing and mechanical weeding are described in detail.

\subsubsection{The multi-year grassland sub-model}

To date, ALOMYSYS only worked with annual crops. The introduction of temporary grassland into ALOMYSYS required adapting various submodels to the persistence of a sown crop cover over several years. There are no changes necessary for the sowing of the perennial crop; its emergence is modelled according to Donatelli and Marchetti (Donatelli and Marchetti, 1994), just as for any annual crop. Blackgrass seedlings emerging before the crop are only affected by intra-specific competition. Seedling mortality is governed by a density-dependent function described by Colbach et al. (2007). After crop emergence, the crop density is also integrated in this function. Because of these densitydependent mortality functions, the later the blackgrass plants emerge in simulated grassland, the less chance they have to survive because of the crop cover and earlier-emerging weeds. Simulations showed that during the subsequent years of grassland cover, survival rates for newly emerged blackgrass seedlings are reduced by approximately $50 \%$ or more, depending on the crop and weed densities, because of the already-existing crop cover.

133 The subsequent growth and development of the few surviving seedlings in perennial crops is assumed

134 to be similar to that in annual winter crops. The main difference occurs at seed shed: in annual crops,

135 the newly produced weed seeds fall on bare or sparsely covered soil, whereas in perennial crops, the

136 seeds are shed on a closed and growing canopy. Many seeds are therefore lost before reaching the soil seed bank. Consequently, in grassland, only $21 \%$ of the produced seeds are added to the seed bank (based on data from Walker et al., 2004 who compared seedling emergence of volunteer and weed seeds broadcasted on grassland vs. bare soil). 
140 A second important difference between annual and multi-annual crops is the possibility of several

141 harvest (without destroying the crop) or mowing operations each year in the latter. Mowing operations

142 are though not specific to multi-annual crops but can also occur in setaside.

\subsubsection{The mowing sub-model}

144 The data for the equations describing the effects of mowing were taken from previous studies 145 (Dalbiès-Dulout, 1999; Dalbiès-Dulout and Doré, 2001). These authors analysed yield components 146 (i.e. number of tillers and heads per plant, number of flowers per head, rate of flowers with a viable 147 seed) and the dates of flowering and seed production of blackgrass plants, depending on mowing dates 148 (ranging from stages 59 to 80, Zadoks et al., 1974) and frequency (none, once, twice), in different 149 years and locations, both in greenhouse and in field experiments.

\subsubsection{Plant mortality}

Dalbiès-Dulout and Doré (2001) did not report any mortality after mowing for plants cut up to maturity onset. The tillers of existing plants were destroyed, but the plants survived to produce new tillers, heads, flowers and seeds. Based on expert opinion, mortality was added in ALOMYSYs for latecut plants that have already started to produce seeds and have less assimilates available for growing new tillers. Thus, plants that present at least one mature head (i.e. with seeds starting to shed) when cut do not survive but their seeds are added to the seed bank.

\subsubsection{Flowering and maturity dates}

160 Dalbiès-Dulout (1999) monitored the dates of flowering and maturity onset in greenhouse and in field trials on blackgrass plants, depending on mowing date and frequency. She found that these factors did not affect the time between mowing and flowering and between mowing and maturity. In ALOMYSYS, flowering of cut plants therefore occurs $368^{\circ} \mathrm{C}$-days (base temperature $0^{\circ} \mathrm{C}$ ) after the last mowing date, the onset of head maturation is fixed at $986^{\circ} \mathrm{C} \cdot$ days after the last mowing date. Only plants cut less than $368^{\circ} \mathrm{C}$-days before the theoretical flowering date are considered to be tall enough to be affected by mowing and have their subsequent growth, development and seed production modified.

\subsubsection{Tillering and head production}

169 In ALOMYSYS, the rates of new tillers and new heads (in fact inflorescences) appearing per unit time 170 remains unchanged by mowing as well as the maximum possible tillers per plant in a given crop 171 environment. With uncut plants, the model uses the foliar time since seedling emergence (i.e. the 172 thermal time since emergence divided by the phyllochrone, the latter being the thermal time between

173 the emission of two successive leaves on the main tiller), with an initial lag of 3 (i.e. no tillers emerge 
before the plant has produced 3 leaves). With cut plants, the thermal time since the last mowing is used instead, without initial lag.

\subsubsection{Number of flowers per head}

When comparing cut vs. uncut plants, Dalbiès-Dulout and Doré (2001) observed a considerable decrease in head lengths, a variable strongly related to the number of flowers (in fact spikelets) per head (Chauvel et al., 2000; Dalbiès-Dulout and Doré, 2001). For very early cut plants, they though reported slight increases in head lengths. ALOMYSYS first calculates the number of flowers per head FH at seed shed for both uncut and cut plants as a function of blackgrass density, crop type and available nitrogen, using the equations from the initial version (Colbach et al., 2007). Then, FH is multiplied for cut plants by a corrective factor based on an analysis of covariance of head lengths of cut vs. uncut plants from Dalbiès-Dulout and Doré (2001): with the date of the last mowing (in ${ }^{\circ} \mathrm{C}$-days since weed emergence) before seed production. The other tested explanatory variables, i.e. mowing frequency, the trial location (field vs. greenhouse) and the weed density were not significant at alpha $=0.05$.

\subsubsection{The rate of flowers with a viable seed}

Blackgrass is a strictly allogamous plant (Johnsson, 1944; Naylor, 1972) and flowers often produce empty seeds. In ALOMYSYS, the rate of flowers with a viable seed SF is calculated at seed shed for both uncut and cut plants, as a function of crop type and blackgrass density (Colbach et al., 2007). Again, a corrective factor is used for cut plants, based on data from the greenhouse trial from DalbièsDulout and Doré (2001): where effect $t_{\text {mowing frequency }}=0.5$ and -0.5 for one and two mowings, respectively. The date at which the plants were cut did not influence their subsequent seed viability rate.

\subsubsection{The mechanical weeding sub-model}

ALOMYSYS distinguishes two types of mechanical weeding operations: hoeing and harrowing. Hoeing is used in large-interrow crops (e.g. sugar beet, maize) and applied solely to the inter-row area (of which the width is chosen by the user) where it (1) uproots all emerged seedlings and (2) covers them with soil. Harrowing is used in cereals and other narrow-row crops and is applied to the whole field, including the crop rows but is less efficient in destroying weeds. It only partially uproots and covers germinated seeds and emerged seedlings. In ALOMYSYS, these functions were based on Kurstjens' 
2000). L. perenne was the only grass species studied by Kurstjens et al. and its seedlings are likely to respond similarly to A. myosuroides.

211 Whatever the tool, the resulting mortality rate of the weeds and the decrease in growth of the surviving

212 weeds then depends on whether the plants were uprooted and/or covered as well as on environmental

213 conditions and various characteristics of the weeding operation. These processes were based on 214 laboratory experiments by Kurstjens and Kropff (2001).

215 In addition, hoeing and harrowing affect soil structure, mix the seeds of the tilled layers and trigger 216 germination of the non-dormant seeds located in these layers of the tilled area. These sub-models for 217 these effects are described by Colbach et al. (2006b).

\subsubsection{The rate of uprooted plants by harrowing and the leaf area covered by soil}

Kurstjens et al. (2000) measured the rate of uprooted plants after harrowing in different soil moisture conditions as a function of tillage characteristics (i.e. working depth, in $\mathrm{mm}$, and speed, in $\mathrm{m} \cdot \mathrm{s}^{-1}$ ). In the present paper, a linear model was fitted to describe the uprooting rate as a function of these variables and of foliar time, keeping only variables significant at alpha $=0.05$ in the final model (PROC GLM of SAS, weighting sum of squares by the number of seedlings in each leaf stage class). To facilitate the use of the resultant model in soil textures other than the sandy soil used in the experiment, soil water potential (MPa) was preferred to soil moisture and was estimated from the soil moisture measured at harrowing using data from Kurstjens (2002), fitting van Genuchten's equation relating soil water potential and moisture (Van Genuchten, 1980). Foliar time $\mathbf{L} \mathbf{P}_{\mathrm{de}}$ was deduced from the plant size actually measured in Kurstjens' experiments by assuming the tallest plants (i.e. $50 \mathrm{~mm}$ ) to have reached the one-leaf stage and germinated but un-emerged seeds at zero leaf: $\log _{\mathrm{e}}\left(\right.$ uprooting rate $\left._{\mathrm{de}}+1\right)=0.0155-0.0215 \cdot \log _{\mathrm{e}}(-$ water potential $)$

Uprooting increased with working depth and speed, but decreased with soil dryness (i.e. - water potential) and with foliar time. Consequently, the older the seedlings, the less sensitive they are to mechanical weeding When introduced into ALOMYSYS, restrictions were added to equation [ 3 ] to keep the uprooting rate within $[0,1]$. For yet un-emerged seedlings, i.e. germinated seeds, the same equation is applied to calculate uprooting rate, with $\mathbf{L} \mathbf{P}_{\mathrm{de}}=0$.

In the same experiment, Kurstjens and Perdok (2000) also measured the relative leaf area covered by soil immediately after harrowing and these data were also fitted with a linear model: 


$$
r^{2}=0.67
$$

The drier the soil (i.e. the larger $\log (-$ water potential)), the deeper and the faster the harrowing operation, the more the seedlings were covered by soil after harrowing. In addition, leaf coverage decreased with foliar time, i.e. the larger the plants the less they were covered by soil. Restrictions were added to equation [ 4 ] to keep the covering rate within $[0,1]$.

\subsubsection{Survival and growth reduction rates of uprooted and non-uprooted plants}

Kurstjens and Kropff (2001) measured the survival rate of uprooted and non-uprooted plants after harrowing, as well as the reduction of growth (i.e. plant biomass relative to plants that were neither uprooted or covered) of the surviving plants. Their data were analysed here with a linear model using soil water potential, working depth and speed as explanatory variables. Only variables and interactions significant at alpha $=0.05$ were kept in the final model:

$$
\begin{aligned}
\text { survival rate }_{\mathrm{de}}=0.960 & -0.0322 \cdot \log _{\mathrm{e}}(- \text { water potential }) \\
& -0.179 \cdot \log _{\mathrm{e}}(\text { working speed }) \\
& -0.0449 \cdot \log _{\mathrm{e}}\left(\mathbf{L P}_{\mathrm{de}}+1\right) \\
\text { survival rate }_{\mathrm{de}}=0.960 & -0.120 \cdot \log _{\mathrm{e}}(- \text { water potential }) \\
& -0.179 \cdot \log _{\mathrm{e}}(\text { working speed }) \\
& -0.156 \cdot \log _{\mathrm{e}}(\text { working depth })
\end{aligned}
$$

For uprooted plants:

$$
\mathrm{R}^{2}=0.84
$$

Even apparently undisturbed, i.e. non-uprooted, plants were affected by harrowing though their survival was considerably higher than for uprooted plants (i.e. a mean survival of $92 \%$ vs. $45 \%$ ). For both uprooted and non-uprooted plants, survival increased with water potential and decreased with working speed. In addition, survival of uprooted plants also decreased with working depth and leaf stage. Similar relationships were found for the relative plant weight of surviving plants after harrowing:

$$
\begin{aligned}
& \log _{\mathrm{e}}\left(\text { relative weight }_{\mathrm{de}}\right)=0.103+0.0691 \cdot \text { water potential } \\
& -0.0475 \text {. leaf cover rate } \text { de }_{\mathrm{d}}
\end{aligned}
$$

275 For uprooted plants:

$$
\begin{aligned}
\log _{\mathrm{e}}\left(\text { relative weight }_{\mathrm{de}}\right)=0.103 & +1.880 \cdot \text { waterpotential } \\
& -0.737 \cdot \text { leaf cover rate } \text { de }_{\mathrm{de}}
\end{aligned}
$$

$$
\mathrm{R}^{2}=0.53
$$

The drier the soil and the more soil on the seedlings, the more the relative weight of the surviving seedlings decreased. Effects were stronger for uprooted vs. non-uprooted seedlings. Restrictions were added to equations [ 5 ] and [ 6 ] to keep the survival and weight rates within $[0,1]$ after introduction into ALOMYSYS. 


\subsubsection{Seedling mortality and growth reduction}

The final effects of harrowing and hoeing depend on whether plants are uprooted and/or covered by soil and result from combining the previous 4 equations, here for instance for survival of emerged seedlings:

$\mathrm{PM} 2_{\mathrm{de}}=\mathrm{PM} 2_{\mathrm{d}-1 \mathrm{e}}$

- (uprooting rate de $_{\mathrm{de}} \cdot$ survival rate $_{\mathrm{de}}[$ uprooted]

$+(1$-uprooting rate de $) \cdot{\left.\text { survival } \text { rate }_{\mathrm{de}}[\text { non-uprooted }]\right)}$

$\mathrm{PM} 22_{\mathrm{de}}$ is the number of plants per $\mathrm{m}^{2}$ present on day $d$ and having emerged on day $e$. For harrowing (or any other tools working both crop rows and interrows), the survival rates are applied to all emerged seedling cohorts as well as germinated seeds located in the layers tilled by the harrow. Figure 1 shows that plant survival decreases with harrowing speed and depth as well as soil dryness and plant stage at harrowing.

The growth reduction rate is used to calculate the decrease in tillering for each seedling cohort by decreasing the maximum possible tiller number in a given crop environment (see chapter 2.1.3.3). The rate of tillers with a head, the number of flowers per head and the rate of flowers with a viable seed were also multiplied by the growth reduction rate. Figure 1 shows that post-harrowing weed growth decreased with working speed and depth as well as soil dryness whereas it increased with plant stage. For hoeing and other tools that only work the interrow area, the field is divided into two subunits, the crop row and the interrow unit. The relative area of the latter unit is chosen by the user (e.g. $70 \%$ of total field area). Survival rates are only applied to seedlings and seeds located in the interrow area. Thus, part of the seedlings are unaffected even by multiple weeding operations and constitute the largest weeds producing most seeds at crop harvest. The effect on tillering, flowers per head and seeds per flower was though not spatialized explicitly (i.e. by calculating separate values for row and interrow plants) to limit necessary computer power and simulation length but resulted from the weighted contributed of row and interrow plants, here for instance for the maximum flowering rate $\mathrm{m}_{\mathrm{de}}$ :

$$
\begin{aligned}
\mathrm{m}_{\mathrm{de}}= & \mathrm{m}_{\mathrm{d}-1 \mathrm{e}} \cdot\left(\mathrm{PM} 2_{\mathrm{de}}[\mathrm{row}] \cdot 1\right. \\
& +\mathrm{PM} 2_{\mathrm{de}}\left[\text { interrow } \cdot \left(\text { uprooting rate }_{\mathrm{de}} \cdot \text { relative weight } \mathrm{de}_{\mathrm{de}}[\text { uprooted }]\right.\right. \\
& \left.+\left(1-\text { uprooting rate }_{\mathrm{de}}\right) \cdot \text { relative weight }_{\mathrm{de}}[\text { non-uprooted }]\right)
\end{aligned}
$$

\subsection{Simulations}

The objective was to test scenarios for converting a standard herbicide-based reference cropping system into an alternative system without any herbicide applications. The alternative scenarios were based on mechanical weeding, mowing and the introduction of multi-year grass land. These techniques were first evaluated individually to identify those of their characteristics mostly influencing weed control. In a second step, comprehensive cropping systems were tested, looking at short, medium and long-term weed control. Statistical analyses not only looked at mean differences between systems, 
but particularly focused on probabilities of obtaining better weed control and on risks of long-term weed increase. Evaluation though only concerned weed control, to the exclusion of more general agronomic, organisational or economic criteria.

\subsubsection{The reference system}

The reference herbicide-base system was a winter oilseed rape (OSR) / winter wheat (WW) / winter barley (WB) rotation, identified as the most common rotation in farm surveys carried out in Côte d'Or, Burgundy (Eastern France) (Colbach et al., 2008). The sowing dates and densities used in the simulation were obtained by averaging actual dates and densities noted for this rotation in the surveys; the same method was used for choosing simulated nitrogen fertilization and harvest (Table 2). The herbicide programme and tillage strategies were those most frequently observed for the OSR/WW/WB rotation. Herbicides were always carried out at optimal conditions and times and achieved the maximum efficiency rate of the product. A slightly modified reference system (called R') was tested where optimal application conditions were only achieved in two years out of three, thus leading to a reduced herbicide efficiency (e.g. $97 \%$ instead of $100 \%$ for grass-targeting herbicide, based on Mamarot and Rodriguez, 2003).

334 Simulations started with an initial blackgrass emergence of 100 plants $/ \mathrm{m}^{2}$ during the crop season and lasted for 27 years. Ten repetitions were carried out for each reference system, by randomly choosing each year annual climate scenarios from weather series from 1986 to 2004 recorded at the meteorological station located at the INRA experimental station at Dijon, France $\left(5^{\circ} 2^{\prime} \mathrm{E}, 47^{\circ} 20^{\prime} \mathrm{N}\right)$. The associated soil climate variables were estimated with the soil-crop model STICS (Brisson et al., 1998b; 2002).

\subsubsection{Single mechanichal weeding tactics}

The objective was to analyse the effect of weeding characteristics (i.e. tool, date, weeded area, working depth and speed) on weed densities at different stages in two crops, either OSR or WW. If hoeing was carried out in WW, interrow width had to be increased, leading to a decrease in sowing

344 density of approximately $25 \%$. The simulations of the weeding scenarios started at the harvest of the 345 previous crop and lasted until the harvest of the analysed crop. The initial seed bank and soil structure at the simulation onset were those left after six (when looking at mechanical weeding in OSR) or seven years (in WW) of the reference system, using median values of seed densities and soil clod distributions from the 10 repetitions of the reference system. There was also one unweeded control scenario. Each scenario was repeated ten times, with the same ten random weather series that were used for the reference system.

The effect of weeding tools and dates on weed infestation at OSR harvest simulated by ALOMYSYS was analysed with linear models, using the GLM procedure of SAS: 
with $\mathrm{i}$ being either hoe or harrow and the repetition indicator $\mathrm{j} \in\{1, \ldots, 10\}$. Weeding dates are in number of days since sowing. Tool $\mathrm{i}_{\mathrm{i}}$ and repetition $_{\mathrm{j}}$ are qualitative variables, weeding date a quantitative variable studied both as primary factor (coefficient $a$ ) and in interaction with the tool (coefficient $b_{\mathrm{i}}$ ). The analysed ALOMYSYS ouput were plant survival after weeding, mature weeds at crop harvest, weed seed production and pre-harvest seed bank (before the new seed rain).

The other characteristics (i.e. area, depth and speed) were analysed, with comparisons of means, using least significant difference tests, after an analysis of variance using the scenario and the repetition as factors.

\subsubsection{Multiple weeding scenarios}

Based on the previous results, a large range of weeding scenarios was compared (see list in Table 3). In addition to the single weeding scenarios analysed previously in OSR, various double and triple scenarios tested different combinations of hoeing and harrowing, with different autumn and spring timings. In WW, there was more emphasis on harrowing which is the more usual tool in WW. In all scenarios, the same simulation protocol as for single weeding tactics was used. For each crop, scenarios were ranked with comparisons of means, using least significant difference tests, after an analysis of variance using the scenario and the repetition as factors.

\subsubsection{Alternative scenarios with tri-annual grassland and mowing}

The effects of mowing dates and frequencies were tested during a three-year simulation with lucerne, starting with the seed bank and soil structure left after a six-year OSR/WW/WB simulation. The other cultivation techniques used to managed lucerne was based on the Côte d'Or farm surveys (Colbach et $a l ., 2008)$. The crop was thus sown without prior tillage on 22 July, with its final harvest on 14 July three years later. Each mowing scenario (see list in Table 4) was repeated ten times, with the same randomly chosen weather series. The seed bank left by the different mowing scenarios after the lucerne harvest (including the last seed rain) was compared, using least significant difference tests, after an analysis of variance using the scenario and the repetition as factors.

\subsubsection{Long-term evaluations of the alternative scenarios}

The best mechanical weeding options for each crop type (i.e. OSR and cereals) were combined and 
27-year-long weather combinations as for the reference simulation. If the alternative scenario was better than the reference (i.e. less infestation than the reference in at least one repetition, never any higher infestation), less stringent weeding options could be tested in the least-risky crops to reduce work and constraints for farmers. Conversely, if the alternative scenario was worse than the reference, additional management options were tested, starting with the most influential cropping system components, i.e. rotation and tillage (Chauvel et al., 2001).

Three criteria were used for comparing the scenarios: the short-term infestation (the density of mature plants averaged over the first three years of the simulation), the medium-term infestation (the same over years 13-15), and the long-term risk (i.e. the correlation between weed densities and years 13-26). For each repetition $\mathrm{j} \in\{1, \ldots, 10\}$, the initial and medium-term infestations of the alternative scenarios were compared with the reference, using the following linear model:

400

401

403 with $\mathrm{k} \in\{1,2,3\}$ (initial infestation) or $\{13,14,15\}$ (medium-term infestation). The scenario $o_{\mathrm{i}}$ values 404 of each alternative scenario $i$ were then compared to the reference value scenario $_{0}$ and the number of repetitions where the infestation of the alternative scenario exceeded the reference scenario was determined. Long-term progress was analysed with Spearman correlations (PROC CORR Spearman of SAS) between weed densities and years for each scenario and repetition and the number of repetitions with a significant positive correlation calculated.

A second series of multi-year simulations consisted in introducing either three or six years of continuous lucerne into the OSR/WW/WB rotation management, alternating with either three or six years of annual crops, respectively. Grassland was managed with the best mowing strategy and the remaining crops with the best mechanical weeding strategy. There was no burial of former crop residues or manure before OSR if the previous crop was lucerne. Weed infestation was analysed with equation [ 10 ] and Spearman correlations.

\section{Results}

\subsection{Short-term effects of mechanical weeding}

\subsubsection{Single mechanical weeding tactics}

419 Plant mortality, weed density at crop harvest, weed seed production and surviving seed bank prior to 420 seed rain all varied with the tool and date of mechanical weeding as well as with the crop (Figure 2). 421 The analysis of the simulation results with linear model [ 9 ] showed that for weeding immediately 
after crop sowing, harrowing was usually more effective than hoeing, i.e. less plants survived weeding and there were less mature weeds, seed production and surviving seed bank at crop harvest (Table 5). Indeed, harrowing tilled $100 \%$ of the field area compared to only $70 \%$ for hoeing. Moreover, interrow width had to be increased to allow hoeing, leading to a decrease in WW sowing densities, thus leaving more space for emerging weeds. Plant mortality after hoeing efficiency though increased with the lateness of the operation while the opposite was true for harrowing which did not uproot the larger weeds found later in season (see equation [ 3 ]). However, when looking at seed production, harrowing had better to be delayed until 2-3 weeks after sowing (Figure 2). Though the plant mortality rate was slightly lower at that date, more blackgrass seedlings had emerged and were affected by the weeding. Earlier weeding operations occurred before or at the onset of the weed emergence flush and could therefore not destroy the weed seedlings. The seed bank prior to the new seed rain always decreased with weeding date, because the weeding tool tilled the soil and triggered seed germination. In OSR, there was though no effect of early weeding on the seed bank because the soil was still too dry for the weeding tool to stimulate much germination.

Despite the inclusion of soil water potential effects in both uprooting and survival equations (see [ 3 ] and [ 5 ]), plant survival after weeding did not vary significantly between repetitions but mostly depended on weeding date (see partial $\mathrm{R}^{2}$ in Table 5). The repetition factor, and therefore weather, significantly influenced the other three analysed weed variables, i.e. mature plants at harvest, seed production and seed bank before seed rain. The relevant weather variable here was soil water potential and its effect on seed germination and seedling emergence, thus influencing weed densities and seed production as well as surviving seeds in the soil.

443 Increasing harrowing speed significantly decreased plant survival though the subsequent effect on mature plants and seed production was slight and the effect on seed bank nil (Table 6). Increasing harrowing depth significantly decreased plant survival but mature plants and seed production were increased because of additional seed germination. Decreasing the width of the hoed interrow area and thus the relative hoed field area considerably increased plant survival and mature plants while seed production was almost doubled. The seed bank was also slightly increased because the narrower hoeing triggered less seed germination.

\subsubsection{Weeding strategies in oilseed rape}

Based on these results, a large range of weeding scenarios were tested. The tested scenarios were ranked according to their seed production (Table 3.A). This variable was thought to synthesize both immediate (seed production is related to weed biomass which causes yield loss) and long-term risks (future infestations). Triple scenarios were best for controlling blackgrass seed production, but only if the last operation in spring was carried out with a hoe. These scenarios divided seed production by nearly 15 compared to the unweeded control. The best triple scenarios were those without harrowing 
or with early harrowing. The later the hoeing operations in the triple scenarios, the better while the opposite was true for harrowing.

The sextuple harrowing was nearly as good as the best triple scenario. Double scenarios performed less well than most triple scenarios. Again, any scenarios with late hoeing were best. Single late autumn hoeings were as good as triple or double harrowings. Any other single scenarios presented little efficiency though all reduced seed production relative to the unweeded control. The ranking of the various scenarios for their effect on the seed bank prior to seed rain was not entirely the same as the ranking obtained for seed production control. Generally, the more operations the less seeds survived because of germination triggering. Harrowing triggered more germinations than hoeing because of the larger tilled area. The sextuple harrowing reduced seed bank by approximately $30 \%$ compared to the control.

\subsubsection{Mechanical weeding in winter wheat}

Table 3.B lists the weeding scenarios tested in WW. The general ranking of the scenarios was slightly different to that observed for OSR, with the sextuple harrowing being the best option. The date of the first operation was a very important factor, with scenarios starting weeding three weeks after sowing (30 Oct.) performing best. Double scenarios ranked better than in OSR as in WW, double scenarios finished with a spring weeding, in contrast to double OSR strategies.

\subsection{Mowing in tri-annual lucerne}

The worst scenarios in lucerne were those with a single mowing (Table 4). Among these, mowing in mid-June was the best option. Advancing the mowing operation to mid-May more than doubled the seed bank because too many blackgrass plants survived to produce seeds later. Delaying mowing to mid-July multiplied the seed bank by 4 because seed shed had already started at that date. Later mowing dates were as bad as the unmown scenario because seed maturation was nearly finished. Double and, even better, triple mowings considerably improved blackgrass control though the efficiency again varied with the mowing dates relative to seed production. Thus, among the double mowing strategies (which all started with a first mowing in mid-May), a too early second mowing (before mid-June) more than tripled the final seed bank compared to a second mowing in mid-June while too late mowing (after July) multiplied it by 30. Among the triple mowings, the best option was mowing every 4-6 weeks, starting in mid-May. Starting mowing only at the end of May multiplied the seed bank by nearly 4 .

\subsection{Evaluation of long-term non-chemical weed management}

Considering the results of the annual simulations on seed production and seed bank (both responsible for long-term infestation), the best multi-year option should consist of triple hoeing in OSR (one and 
scenario). A slightly less efficient scenario would consist in triple hoeing in all crops which would reduce the workload for the farmer.

493 During the first years of the multi-year simulation, the blackgrass infestation in these two scenarios was 2-3 times higher than in the herbicide-based reference scenario $\mathrm{R}$ (Table 7). Over time, the difference between the alternative and the reference scenarios increased considerably (Figure 3). At medium-term, M1 and M2 exceeded the reference scenario in all repetitions, with the highest weed densities in M2 (Table 7) as triple hoeing in cereals was shown to control seed production less well than sextuple harrowing (Table 3.B). At long term, the R and M2 scenarios presented stable or decreasing infestations as their mean Spearman correlation coefficient was lower than zero (pointing to a decrease in weed densities with time) and in none of the ten repetitions significantly higher than zero. The long-term M1 dynamics were slightly less stable as infestations significantly increased in one of the repetitions.

As the M1 and M2 strategies did not manage to keep infestations at a low and stable level, the idea of the L1 scenario was to diversify the rotation by introducing a three-year lucerne managed with the optimal mowing strategy identified in Table 4 (i.e. mowing thrice every year at 4-6 weeks intervals, starting in mid-May), resulting in a six-year rotation OSR/WW/WB/3-year lucerne. The infestation during the lucerne was close to zero though it again soared during the three years of annual crops (Figure 3). Indeed, the blackgrass seeds survived quite well during the three years of lucerne where no tillage operations stimulated seed germination. Despite this high seed survival, infestations during the annual crops were divided by more than ten compared to the M1 scenario and slightly decreased over time. Medium-term infestations in the L1 scenario were though still higher than in the R scenario (Table 7). The infestation was even worse if the rotation alternated six years of annual crops and six years of continuous lucerne (L2 of Table 7). The slow seed bank depletion during the lucerne was not sufficient to compensate the increased weed seed production during the six continuous years of annual crops. To address this problem of insufficient seed bank reduction, the L3 scenario tilled the field before sowing the three-year lucerne to increase fatal seed germination. This strategy considerably decreased mid-term infestations though long-term dynamics became more unstable, i.e. in three out of ten repetitions, infestations increased significantly.

As seed bank management proved crucial for blackgrass control, the last series of multi-year simulations tested the introduction of mouldboard ploughing to both stimulate fatal seed germination and limit in-crop weed emergence. Ploughing each year before the annual crops (P1 scenario) was sufficient to reduce blackgrass to a level comparable to the herbicide-based $\mathrm{R}$ system though longterm dynamics were still unstable. As ploughing though requires more time and fuel than other tillage operations, the remaining three P scenarios only ploughed before either OSR, WW or WB. Though short-term infestation increased slightly, the reduced ploughing frequency was sufficient to control 
second annual crop, i.e. WW (P3 scenario). In that case, long-term dynamics became even more stable

528 than in the P1 scenario.

529

\section{Discussion}

\subsection{Modelling approach}

The present modelling approach was based on a process-based representation of effects of techniques and their interactions with environmental conditions. These experimental data were preferred to synthetic observations from field trials (e.g. Rasmussen, 1992) because mechanical weeding and, to a lesser degree, mowing have complex and sometimes compensating effects (e.g. seedling mortality vs. triggering of seed germination by tillage) that interact with environmental conditions and weed stages. This approach could be taken because Kurstjens et al. set up detailed experiments to assess the various differential effects (e.g. uprooting, covering plants with soil) in interaction with environment (e.g. soil moisture), weeding characteristics (depth, speed) and weed stages. Similarly, Dalbiès-Dulout and Doré analysed the effect of mowing characteristics on the different stages and yield components of blackgrass. The addition of these various processes to the existing ALOMYSYS model was only possible because of its modular structure and its strong focus on a mechanistic representation of interactions. These characteristics also ease the addition of other weeding implements (e.g. Chicouene, 2007) and preventive tactics.

However, the disadvantage of this approach is the high number of required condition-specific relationships. This particularly holds for the mechanical weeding submodel. The effect of soil conditions and weed growth stage can only be separated by assessing the height or mass of individual weeds. The necessary data were taken from laboratory experiments because these are the only data on weed survival and growth reduction that are specific for weed size and types of damage as created by implements. Principally, data from articifial physical damaging experiments (Habel, 1954; Jones et al., 1995; , 1996; Baerveldt and Ascard, 1999) could have been used as well in this approach, but the representativeness of the artificial damaging is very important though uncertain (Kurstjens and Kropff, 2001).

If condition-specific relationships could only be derived from laboratory experiments, the consistence with field conditions would be a principal weakness of the approach used here. In Kurstjens' laboratory experiments with homogeneous sandy soil and absence of rain, large uprooted plants had little chance of surviving. Their survival chance might be better in other, more clayey textures where, conversely, uprooting might work better in drier vs. moist conditions. The adaptation of the submodel parameters to other soil textures could be dealt with by additional experiments or expert opinion. The constant climate chamber conditions and the absence of rain in the laboratory experiments do not adequately represent field conditions. In real fields, the post-harrowing weather with its daily rhythms of temperature, wind, radiation and humidity governs the survival of uprooted seedlings. For instance, 
root balls of large plants can reconnect to the soil after rain and thus survive better as predicted by the present model. The survival of large uprooted plants was therefore probably underestimated, especially as the experiments only worked with plants up to one leaf. However, assessing the effects of environmental conditions on weed dynamics in fields poses a more fundamental problem, because the observed plant survival and growth reduction are the result of various distinct processes that are difficult to discriminate and measure in fields. Consequently, highly conditioned laboratory experiments play a crucial role.

To orientate future attempts for evaluating and improving the model, analysing the sensitivity of the model output to the various parameters describing the effects of the newly added techniques would be helpful. The authors are presently working on a series of virtual experiments with contrasted cropping systems where the model parameters are made to vary randomly, using techniques of sensitivity analyses already applied to other complex cropping system models (e.g. Colbach et al., 2009).

\subsection{Preliminary model evaluation}

The simulations of mechanical weeding operations showed low efficiency of weed harrow expressed as percentage of seedling killed, even for early harrowings (and thus young seedlings). This is in accordance with experimental data of Kurstjens and Kropff (2001) who reported mortalities ranging from 10 to $30 \%$ for the grass weed Lolium perenne. The efficiency though varies considerably with the tool and the seedling stage at weeding. For instance, Kurstjens (2007) reported efficiencies of intra-row mechanical weeding reaching up to $70 \%$ for young seedlings, just as for late hoeing in the present simulations. French extension services report similar weeding efficiencies on their multi-local field experiment for very young grass weed seedlings just after emergence (first leaf not yet fully expanded). This mortality rate is indeed higher than the one obtained here when evaluating the weeding tactics and scenarios. However, the model sensitivity analysis showed plant survival to vary considerably with harrowing characteristics and conditions; it moreover predicted plant mortality rates similar to those observed by the extension services for very young plants or faster and deeper harrowing. In the simulations, seedling populations though consisted of both young and older plants with the latter surviving quite well after harrowing. In addition, weeding operations were simulated at fixed and not necessarily optimal dates whereas in field experiments, the timing of the operations was optimised relative to soil moisture.

The frequency and timing of mowing relative to weed stages, particularly the onset of seed production, was crucial in the present simulations. There are only a few reports in literature on the impact of cutting on blackgrass. As in the present simulations, Meiss et al. (2008) reported decreasing survival and biomass production with increasing plant stage at mowing. Conversely, Andreasen et al. (2002) did not observe any plant stage effect for the sole grass species they studied but they cut their plants very early, without much timing difference (i.e. 2 and 3-leaf stage, respectively), and only looked at short-term biomass production. 
Though blackgrass decreased in rotations with 3-year lucerne, infestations in the annual crops were still high. This was, at first, surprising as temporary grassland is usually considered a weedsuppressing crop (Bellinder et al., 2004; Teasdale et al., 2004; Albrecht, 2005; Heggenstaller and Liebman, 2006). However, blackgrass seeds survive quite well in the absence of germinationtriggering tillage and/or when buried at depths where germination is inhibited (Lonchamp et al., 1984; Colbach et al., 2006a). So even though blackgrass seed production is nil or negligible in perennial canopies, the seed bank left after the temporary grassland is still important. It is probable that the introduction into the rotation of spring crops (where blackgrass emerges and reproduces badly, Colbach et al., 2007) might be more interesting because of frequent germination-triggering tillage operations.

Though these first comparisons to literature reports are encouraging, the submodels added here to ALOMYSYS must be evaluated with independent field data, to determine the conditions in which the model can be safely used, its prediction error as well as deficiencies that must be corrected in future. This evaluation should be conducted at two levels, just as in the simulations carried out here. In the case of mechanical weeding, annual trials should monitor weed survival and reproduction as well as environmental conditions in treatments combining different tools, working depths, soil moisture conditions etc. Multi-year cropping system trials should complete this analysis by looking at weed dynamics over several years, albeit with less detail and frequency. A similar approach was indeed used to evaluate the initial version of ALOMYSYS, looking in detail at weekly emergence in short-term trials (Colbach et al., 2006a)and at multi-year dynamics in long-term cropping systems (Colbach et al., 2007).

\subsection{Implications for weed management}

The simulations show that non-chemical weed control can neither be reasoned at short-term nor replace herbicides; when combined with other cultivation techniques, non-chemical weed control can though be as efficient as herbicide-based systems. In a long-term experiment testing cropping system prototypes based on Integrated Weed Management, mechanical weeding proved to be very useful in controlling blackgrass efficiently with little or no herbicides, provided that it was associated with a diversified crop rotation, stale seed bed techniques, delayed cereal sowing, competitive cultivars, high sowing densities, reduced inter-row distance, ... (Chikowo et al., 2009). In the present study, only a limited number of strategies were tested for a single rotation typical of Burgundy, but practical conclusions can already be drawn for advising farmers. The good news for farmers is that wellreasoned mechanical weeding combined with other judiciously chosen modifications in the cropping system is viable at long-term and as good as herbicide strategies. The bad news is that inadequate timing of mechanical weeding or mowing can increase blackgrass infestation, not only because of insufficient control, but, in the case of mechanical weeding also because of subsequent germination and emergence flushes caused by the weeding tool. In addition, the diversification of the intensive 
634 rotation by introducing a perennial legume crop (a frequent strategy in organic farming) was not as

635 efficient as expected. Introducing spring crops preceded by stale seed bank techniques would be much

636 more interesting for managing blackgrass (Chauvel et al., 2001; Colbach et al., 2007; Chauvel et al., 637 2009).

638 The simulated efficiency of mechanical weeding control and other weed-relevant cultivation 639 techniques could probably be improved if crop management was not considered as a fixed programme 640 where operations are always carried out at the same date, irrespective of weather or soil conditions. 641 Indeed, the present simulations showed that weather conditions have a large impact on weed control 642 effectiveness. If the simulated operation timing depended on prevailing weather conditions, mimicking 643 the decision making of farmers waiting for the good conditions to implement the mechanical weeding, 644 weeding efficiency would increase and vary less between years. If decision-rule models (Bergez et al., 645 2002; Keating et al., 2003; Chatelin et al., 2005) could be connected to ALOMYSYS to take account of 646 practical guidelines (depending on weather, soil moisture and crop and weed growth stage) and 647 trafficability restrictions. Simulations would thus be more robust and used to improve guidelines, to 648 assess risks and associated costs (crop damage, hand weeding, future control demands).

649 Moreover, the present study focused on a single particular weed species, i.e. blackgrass, and cannot be 650 extrapolated to other species. Indeed, mechanical weeding is thus more efficient for controlling 651 broadleaved vs. grass species (http://www.agri02.com/_Documents/Telecharge/herse_etrille.pdf) 652 whereas species with short-lived and/or easily germinating seeds will rapidly disappear in rotations 653 with multi-year crops (Clay and Aguilar, 1998; Ominski et al., 1999; Schoofs and Entz, 2000; Entz et 654 al., 2002; Porter et al., 2003). Conversely, small plants (e.g. Veronica sp.) will not be affected by 655 mowing though they often reproduce badly in taller crops (Meiss et al., 2008). Consequently, the 656 authors are presently working on extrapolating the ALOMYSYS model to a multi-specific weed flora 657 (Gardarin et al., ; Gardarin, 2008).

658 In this study, the weed management strategies were evaluated considering only their efficiency for 659 short and long-term weed control. This criterion is obviously not sufficient for providing a 660 comprehensive assessment of sustainability at the cropping system level. In some cases mechanical 661 weeding can damage the crop and restrict the yield (Melander et al., 2008) and therefore the economic 662 performance of the system. Mechanical weeding and tillage both require energy inputs, and the 663 diversification of the crop sequence with legume crops also affects the energy balance of the system 664 and possibly greenhouse-gas emissions. These issues will have to be considered in further assessments 665 of alternative weed management strategies designed from model simulations.

666 


\section{Acknowledgements}

669

670

671

The present work was financed by INRA, ANR OGM VIGIWEED (ANR-07-POGM-003-01) and ANR SYSTERRA ADVHERB (ANR-08-STRA-02).

\section{References}

Albrecht, H., 2005. Development of arable weed seedbanks during the 6 years after the change from conventional to organic farming. Weed Research 45, 339-350.

Andreasen, C., Hansen, C. H., Moller, C., Kjaer-Pedersen, N. K., 2002. Regrowth of weed species after cutting. Weed Technology 16, 873-879.

Aubertot, J. N., Lescourret, F., Bonato, O., Colbach, N., Debaeke, P., Doré, T., Fargues, J., Lô-Pelzer, E., Loyce, C., Sauphanor, B., How to improve pest management in cropping systems. Effects of cultural practices on pest development. A review. Agronomy for Sustainable Development

Baerveldt, S., Ascard, J., 1999. Effect of soil cover on weeds. Biological Agriculture and Horticulture 17, 101-111.

Bellinder, R. R., Dillard, H. R., Shah, D. A., 2004. Weed seedbank community responses to crop rotation schemes. Crop Protection 23, 95-101.

Bergez, J. E., Deumier, J. M., Lacroix, B., Leroy, P., Wallach, D., 2002. Improving irrigation schedules by using a biophysical and a decisional model. European Journal of Agronomy 16, 123-135.

Brisson, N., Mary, B., Ripoche, D., Jeuffroy, M. H., Ruget, F., Nicoullaud, B., Gate, P., DevienneBarret, F., Antonioletti, R., Durr, C., Richard, G., Beaudoin, N., Recous, S., Tayot, X., Plenet, D., Cellier, P., Machet, J. M., Meynard, J. M., Delecolle, R., 1998a. STICS: a generic model for the simulation of crops and their water and nitrogen balances. I. Theory and parameterization applied to wheat and corn. Agronomie 18, 311-346.

Brisson, N., Mary, B., Ripoche, D., Jeuffroy, M. H., Ruget, F., Nicoullaud, B., Gate, P., DevienneBarret, F., Antonioletti, R., Durr, C., Richard, G., Beaudoin, N., Recous, S., Tayot, X., Plenet, D., Cellier, P., Machet, J. M., Meynard, J. M., Delécolle, R., 1998b. STICS : a generic model for the simulation of crops and their water and nitrogen balances. I. Theory and parameterization applied to wheat and corn. Agronomie 18, 311-346.

Brisson, N., Ruguet, F., Gate, P., J., L., Nicoullaud, B., Tayot, X., Plenet, D., Jeuffroy, M. H., Bouthier, A., Ripoche, D., Mary, B., Justes, E., 2002. STICS : a generic model for simulating crops and their water and nitrogen balances. II. Model validation for wheat and maize. Agronomie 22, 69-92.

Chatelin, M. H., Aubry, C., Poussin, J. C., Meynard, J. M., Masse, J., Verjux, N., Gate, P., Le Bris, X., 2005. DéciBlé, a software package for wheat crop management simulation. Agricultural Systems 83, 77-99.

Chauvel, B., Munier-Jolain, N., Letouzé, A., Grandgirard, D., 2000. Developmental pattern of leaves and tillers in a black grass population (Alopecurus myosuroides Huds.). Agronomie 20, 247257.

Chauvel, B., Guillemin, J. P., Colbach, N., Gasquez, J., 2001. Evaluation of cropping systems for management of herbicide-resistant populations of blackgrass (Alopecurus myosuroides Huds.). Crop Protection 19, 127-137.

Chauvel, B., Guillemin, J. P., Colbach, N., 2009. Evolution of a herbicide-resistant population of Alopecurus myosuroides Huds. in a long-term cropping system experiment. Crop Protection 28, 343-349.

Chicouene, D., 2007. Mechanical destruction of weeds. A review. Agronomy for Sustainable Development 27, 19-27.

Chikowo, R., Faloya, V., Petit, S., Munier-Jolain, N., 2009. Integrated Weed Management systems allow reduced reliance on herbicides and long term weed control. Agriculture, Ecosystems and Environment 132, 237-242. 
Clay, S. A., Aguilar, I., 1998. Weed seedbanks and corn growth following continuous corn or alfalfa. Agronomy Journal 90, 813-818.

Colbach, N., Debaeke, P., 1998. Integrating crop management and crop rotation effects into models of weed population dynamics: a review. Weed Science 46, 717-728.

Colbach, N., Dürr, C., Roger-Estrade, J., Caneill, J., 2005. How to model the effects of farming practices on weed emergence. Weed Research 45, 2-17.

Colbach, N., Busset, H., Yamada, O., Dürr, C., Caneill, J., 2006a. ALOMYSYS: modelling blackgrass (Alopecurus myosuroides Huds.) germination and emergence, in interaction with seed characteristics, tillage and soil climate. II. Evaluation. European Journal of Agronomy 24, 113-128.

Colbach, N., Dürr, C., Roger-Estrade, J., Chauvel, B., Caneill, J., 2006b. ALOMYSYS: modelling blackgrass (Alopecurus myosuroides Huds.) germination and emergence, in interaction with seed characteristics, tillage and soil climate. I. Construction. European Journal of Agronomy 24, 95-112.

Colbach, N., Chauvel, B., Gauvrit, C., Munier-Jolain, N. M., 2007. Construction and evaluation of ALOMYSYS, modelling the effects of cropping systems on the blackgrass life-cycle. From seedling to seed production. Ecological Modelling 201, 283-300.

Colbach, N., Sassi, A., Granger, S., 2008. ALOMYSYS: a model for evaluating and developing cropping systems for integrated weed management. In: 10th congress of the European Society for Agronomy, Bologne (Italie), 15-19 septembre 2008,

Colbach, N., Darmency, H., Tricault, Y., 2009. Identifying key life traits for the dynamics and gene flow in a weedy crop relative: sensitivity analysis of the GeneSys simulation model for weed beet Ecological Modelling doi:10.1016/j.ecolmodel.2009.10.011.

Dalbiès-Dulout, A., 1999. Contribution au diagnostic et à la prévision des effets précédent du gel des terres annuel. Institut National Agronomique Paris-Grignon, Paris.

Dalbiès-Dulout, A., Doré, T., 2001. Management of inflorescence and viable seed production of blackgrass (Alopecurus myosuroides) on set-aside in France. Crop Protection 20, 221-227.

Darmency, H., Gasquez, J., 1990. Résistances aux herbicides chez les mauvaises herbes. Agronomie 6, 457-472.

Donatelli, M., Marchetti, R., 1994. A multi-crop submodel to predict emergence time: model definition and preliminary testing. In: 3rd ESA Congress, Abano-Padova, Italy, 350-351.

Doyle, C. J., 1997. A review of the use of models of weed control in Integrated Crop Protection. In: Agriculture, Ecosystems \& Environment,

Entz, M. H., Baron, V. S., Carr, P. M., Meyer, D. W., Smith, S. R., McCaughey, W. P., 2002. Potential of forages to diversify cropping systems in the northern Great Plains. Agronomy Journal 94, 240-250.

Gardarin, A., Dürr, C., Colbach, N., Effects of seed depth and soil structure on the emergence of weeds with contrasted seed traits. Weed Research in press.

Gardarin, A., 2008. Modélisation des effets des systèmes de culture sur la levée des advnetices à partir de relations fonctionnelles utilisant les traits des espèces. Université de Bourgogne, Dijon, France.

Gasquez, J., 1996. État de la résistance aux herbicides en France. In: Xème Colloque International sur la Biologie des Mauvaises Herbes, Dijon, France, 173-180.

Gressel, J., Segel, L. A., 1990. Modelling the effectiveness of herbicide rotations and mixtures as strategies to delay or preclude resistance. Weed Technology 4, 186-198.

Habel, W., 1954. Über die Wirkungsweise der Eggen gegen Samenunkräuter sowie die Empfindlichkeit der Unkrautarten und ihrer Altersstadien gegen den Eggvorgang. Landwirtschaftlichen Hochschule Hohenheim, Hohenheim, Germany.

Heggenstaller, A. H., Liebman, M., 2006. Demography of Abutilon theophrasti and Setaria faberi in three crop rotation systems. Weed Research 46, 138-151.

Hole, S. J. W., Powles, S. B., 1997. Reduced efficacy and enhanced degradation of carbetamide after repeated application in Australia. Weed Research 37, 165-170.

Holst, N., Rasmussen, I. A., Bastiaans, L., 2007. Field weed population dynamics: a review of model approaches and applications. Weed Research 47, 1-14.

IFEN, 2007. Les pesticides dans les eaux - Données 2005. Institut français de l'environnement, 37 p. 
Johnsson, H., 1944. Meiotic aberrations and sterility in Alopecurus myosuroides Huds. Hereditas 30, 469-565.

Jones, P. A., Blair, A. M., Orson, J. H., 1995. The effect of different types of physical damage to four weed species. In: Brighton Crop Protection Conference - Weeds, Brighton, United Kingdom, 1995, 653-658.

Jones, P. A., Blair, A. M., Orson, J. H., 1996. Mechanical damage to kill weeds. In: Second International Weed Control Congress, Copenhagen, Denmark, 1996, 949-954.

Keating, B. A., Carberry, P. S., Hammer, G. L., Probert, M. E., Robertson, M. J., Holzworth, D., Huth, N. I., Hargreaves, J. N. G., Meinke, H., Hochman, Z., McLean, G., Verburg, K., Snow, V., Dimes, J. P., Silburn, M., Wang, E., Brown, S., Bristow, K. L., Asseng, S., Chapman, S., McCown, R. L., Freebairn, D. M., Smith, C. J., 2003. An overview of APSIM, a model designed for farming systems simulation. European Journal of Agronomy 18, 267-288.

Kurstjens, D. A. G., Perdok, U. D., 2000. The selective soil covering mechanism of weed harrows on sandy soil. Weed Research 55, 193-206.

Kurstjens, D. A. G., Perdok, U. D., Goense, D., 2000. Selective uprooting by weed harrowing on sandy soils. Weed Research 40, 431-447.

Kurstjens, D. A. G., Kropff, M. J., 2001. The impact of uprooting and soil-covering on the effectiveness of weed harrowing. Weed Research 41, 211-228.

Kurstjens, D. A. G., 2002. Mechanisms of selective mechanical weed control by harrowing. PhD Thesis, Wageningen University, The Netherlands.

Lonchamp, J. P., Chadoeuf, R., Barralis, G., 1984. Évolution de la capacité de germination des semences de mauvaises herbes enfouies dans le sol. Agronomie 4, 671-682.

Mamarot, J., Rodriguez, A., 2003. Sensibilité des mauvaises herbes aux herbicides en grandes cultures. ACTA, Paris, 372 p.

Meiss, H., Munier-Jolain, N., Henriot, F., Caneill, J., 2008. Effects of biomass, age and functional traits on regrowth of arable weeds after cutting. Journal of Plant Diseases and Protection 493499.

Melander, B., Holst, N., Jensen, P. K., Hansen, E. M., Olesen, J. E., 2008. <i>Apera spica-venti</i> population dynamics and impact on crop yield as affected by tillage, crop rotation, location and herbicide programmes. Weed Research 48, 48-57.

Moss, S. R., 1987. Herbicide resistance in black-grass (Alopecurus myosuroides Huds.). In: Proceedings 1987 British Crop Protection Conference-Weeds Brighton, England, 879-886.

Naylor, R. E. L., 1972. Biological flora of the British isles. Alopecurus myosuroides Huds. Journal of Ecology 60, 611-622.

Ominski, P. D., Entz, M. H., Kenkel, N., 1999. Weed suppression by Medicago sativa in subsequent cereal crops: a comparative survey. Weed Science 47, 282-290.

Porter, P. M., Huggins, D. R., Perillo, C. A., Quiring, S. R., Crookston, R. K., 2003. Organic and other management strategies with two- and four-year crop rotations in Minnesota. Agronomy Journal 95, 233-244.

Rasmussen, J., 1992. Testing harrows for mechanical control of annual weeds in agricultural crops. Weed Research. 32, 267-274.

Rossing, W. A. H., Meynard, J. M., van, I., M.K., 1997. Model-based explorations to support development of sustainable systems: case studies from France and the Netherlands. European Journal of Agronomy 7, 271-283.

Schoofs, A., Entz, M. H., 2000. Influence of annual forages on weed dynamics in a cropping system. Canadian Journal of Plant Science 80, 187-198.

Teasdale, J. R., Mangum, R. W., Radhakrishnan, J., Cavigelli, M. A., 2004. Weed seedbank dynamics in three organic farming crop rotations. Agronomy Journal 96, 1429-1435.

Van Der Weide, R. Y., Bleeker, P. O., Achten, V. T. J. M., Lotz, L. A. P., Fogelberg, F., Melander, B., 2008. Innovation in mechanical weed control in crop rows. Weed Research 48, 215-224.

Van Genuchten, M. T., 1980. A close form equation for predicting the hydraulic conductivity of unsaturated soils. Soil Science Society of America Journal 44, 892-898.

Van Himme, M., Bulcke, R., 1975. Distribution, extension et importance d'Alopecurus myosuroides Huds. en Europe. In: Proceedings European Weed Research Society Symposium Status, Biology and control of grassweeds in Europe, 23-54. 
Walker, R. L., Booth, E. J., Whytock, G. P., Walker, K. C., 2004. Volunteer potential of genetically modified oilseed rape with altered fatty acid content. Agriculture Ecosystems \& Environment 104, 653-661.

Zadoks, J. C., Chang, T. T., Konzak, C. F., 1974. A decimal code for the growth stages of cereals. Weed Research. 14, 415-421. 
Table 1. Effects of cropping system on the blackgrass life-cycle (density and timing of stages) as simulated by ALOMYSyS (Colbach et al., 2006b; Colbach et al., 2007).

\begin{tabular}{|c|c|c|}
\hline $\begin{array}{l}\text { Cropping } \\
\text { system }\end{array}$ & Intermediate effect & Effect on blackgrass \\
\hline Sowing date & $\begin{array}{l}\text { Crop emergence date } \\
\text { Date of last tillage }\end{array}$ & $\begin{array}{l}\text { The earlier the weed seedlings emerge relative to the crop, the better they survive } \\
\text { The later the last tillage, the more weed seeds have germinated already and are killed by the tillage }\end{array}$ \\
\hline $\begin{array}{l}\text { Nitrogen } \\
\text { fertiliser }\end{array}$ & & $\begin{array}{l}\text { Increases flowers/head } \\
\text { Increases primary dormancy; germination of newly produced seeds is spread of a longer period }\end{array}$ \\
\hline Harvest & & $\begin{array}{l}\text { Destruction of all plants } \\
\text { Addition of newly produced seeds to seed bank }\end{array}$ \\
\hline
\end{tabular}


Table 2.

Crop management in the herbicide-based reference system of the oilseed rape/winter wheat/winter barley rotation.

\begin{tabular}{|c|c|c|c|}
\hline Cultivation technique & Oilseed rape & Winter wheat & Winter barley \\
\hline Tillage & $\begin{array}{l}\text { Chisel (15 July) } \\
2 \text { x covercrop (1 Aug.) } \\
\text { Power harrow (15 Aug.) } \\
\text { Spring tine (27 Aug.) }\end{array}$ & $\begin{array}{l}\text { Chisel (15 Aug.) } \\
\text { Chisel (10 Sept.) } \\
\text { Spring tine (10 Oct.) }\end{array}$ & $\begin{array}{l}\text { Covercrop (1 aug.) } \\
\text { Chisel (21 Aug.) } \\
\text { Spring tine (10 Sept.) } \\
\text { Power harrow (8 Oct.) }\end{array}$ \\
\hline $\begin{array}{l}\text { Sowing date } \\
\text { Sowing density } \\
\left(\text { seeds } / \mathrm{m}^{2}\right)\end{array}$ & $\begin{array}{l}27 \text { Aug. } \\
56\end{array}$ & $\begin{array}{l}10 \text { Oct. } \\
344\end{array}$ & $\begin{array}{l}8 \text { Oct. } \\
330\end{array}$ \\
\hline Herbicides $^{1}$ & $\begin{array}{l}\text { trifluraline ( } 26 \text { Aug.) } \\
\text { napropamide ( } 26 \text { Aug.) } \\
\text { clomazone + dimétachlore + napropamide } \\
\text { (26 Aug.) } \\
\text { quizalofop-éthyl isomère D ( } 5 \text { Oct.) }\end{array}$ & $\begin{array}{l}\text { iodosulfuron-méthyl-sodium + mésosulfuron-méthyl } \\
\text { (12 March) } \\
24 \mathrm{MCPA}+\text { fluroxypyr + clopyralid (5 April) }\end{array}$ & $\begin{array}{l}\text { imazaméthabenz-méthyl ( } 7 \\
\text { Nov.) } \\
\text { isoproturon ( } 7 \text { Nov.) }\end{array}$ \\
\hline Harvest date & 12 July & 18 July & 2 July \\
\hline
\end{tabular}

Soil texture was $36 \%$ clay, $58 \%$ loam and $6 \%$ sand, with $1 \%$ of stones. Soil depth was $90 \mathrm{~cm}$.

${ }^{1}$ Herbicides were never applied at the total regulatory rate, but usually at only $66-80 \%$ of the rate. Applications were carried out at optimal conditions and times and therefore still produced the maximum efficiency rate of the product. 
Table 3. Ranking of the tested weeding scenarios for controlling blackgrass seed production and seed bank. Simulations with ALOMYSYS

A. Oilseed rape.

\begin{tabular}{|c|c|c|c|c|c|c|c|c|c|c|c|c|}
\hline \multicolumn{6}{|c|}{ Weeding scenarios } & \multirow{2}{*}{\multicolumn{3}{|c|}{$\begin{array}{l}\text { Seed production } \\
\left(\text { seeds } / \mathrm{m}^{2}\right)\end{array}$}} & & \multirow{2}{*}{\multicolumn{3}{|c|}{$\begin{array}{l}\text { Seed bank before } \\
\text { seed rain }\left(\text { seeds } / \mathrm{m}^{2}\right)\end{array}$}} \\
\hline \multicolumn{2}{|c|}{$1^{\text {st }}$ operation } & \multicolumn{2}{|c|}{$2^{\text {nd }}$ operation } & \multicolumn{2}{|c|}{$3^{\text {rd }}$ operation } & & & & & & & \\
\hline Hoe & 23 Sept. & Hoe & 21 Oct. & Hoe & 1 April & $13650 \mathrm{n}$ & & & & 242 & & $\mathrm{~h}$ \\
\hline Harrow & & & & & & $15417 n$ & & $\mathrm{~m}$ & & 214 & & i \\
\hline Harrow & 9 Sept. & Hoe & 23 Sept. & Hoe & 1 April & $15595 n$ & & $\mathrm{~m}$ & & 247 & & $\mathrm{~h}$ \\
\hline Harrow & 16 Sept. & Hoe & 16 Sept. & Hoe & 1 April & $16203 n$ & & $\mathrm{~m}$ & & 246 & & $\mathrm{~h}$ \\
\hline Harrow & 16 Sept. & Hoe & 23 Sept. & Hoe & 1 April & $16741 \mathrm{n}$ & & $\mathrm{m}$ & & 244 & & $\mathrm{~h}$ \\
\hline Hoe & 23 Sept. & Harrow & 21 Oct. & Hoe & 1 April & $16979 n$ & & $\mathrm{~m}$ & & 239 & & $\mathrm{~h}$ \\
\hline Harrow & 23 Sept. & Hoe & 21 Oct. & Hoe & 1 April & $18385 n$ & & $\mathrm{~m}$ & & 238 & & $\mathrm{~h}$ \\
\hline Hoe & 23 Sept. & Hoe & 21 Oct. & Harrow & 1 April & $18762 n$ & & $\mathrm{~m}$ & & 242 & & $\mathrm{~h}$ \\
\hline Harrow & 23 Sept. & Harrow & 21 Oct. & Hoe & 1 April & $21263 n$ & & $\mathrm{~m}$ & I & 235 & & $\mathrm{~h}$ \\
\hline Hoe & 23 Sept. & Hoe & 21 Oct. & & & $21749 n$ & & $\mathrm{~m}$ & I & 272 & $g$ & $f$ \\
\hline Hoe & 9 Sept. & Hoe & 23 Sept. & & & $21972 n$ & & $\mathrm{~m} \mathrm{k}$ & i & 279 & & $f$ \\
\hline Harrow & 23 Sept. & Hoe & 21 Oct. & Harrow & 1 April & $23650 n$ & & $\mathrm{~m} \mathrm{k}$ & i & 238 & & $\mathrm{~h}$ \\
\hline Harrow & 23 Sept. & Hoe & 21 Oct. & & & $27009 n$ & & $\mathrm{~m} \mathrm{k}$ & i & 265 & $\mathrm{~g}$ & $f$ \\
\hline Harrow & 9 Sept. & Hoe & 23 Sept. & & & $27292 n$ & & $\mathrm{~m} \mathrm{k}$ & I & 272 & $\mathrm{~g}$ & $f$ \\
\hline Hoe & 23 Sept. & Harrow & 21 Oct. & Harrow & 1 April & $32775 n$ & & $\mathrm{~m} \mathrm{k}$ & I & 239 & & $\mathrm{~h}$ \\
\hline Hoe & 9 Sept. & Harrow & 23 Sept. & & & 37563 & & $\mathrm{~m} \mathrm{k}$ & I & 277 & $g$ & $f$ \\
\hline Hoe & 23 Sept. & Harrow & 21 Oct. & & & 42413 & & $\mathrm{k}$ & I & 269 & $\mathrm{~g}$ & $f$ \\
\hline Hoe & 21 Oct. & & & & & 44654 & & i k & & 277 & $g$ & $f$ \\
\hline Hoe & 24 Nov. & & & & & 50835 & & i & $\mathrm{h}$ & 272 & g & $f$ \\
\hline Harrow & 23 Sept. & Harrow & 21 Oct. & Harrow & 1 April & 53304 & & $\mathrm{ig}$ & h & 236 & & $\mathrm{~h}$ \\
\hline $\mathrm{Hoe}$ & 1 April & & & & & 54201 & J & $\mathrm{ig}$ & h & 273 & $g$ & $f$ \\
\hline Hoe & 23 Sept. & & & & & 55139 & & i g & $\mathrm{h}$ & 311 & $\mathrm{e}$ & d \\
\hline Harrow & 9 Sept. & Harrow & 23 Sept. & & & 67178 & $f$ & i g & $\mathrm{h}$ & 271 & g & $f$ \\
\hline Hoe & 16 Sept. & & & & & 68714 & $f$ & $\mathrm{~g}$ & h & 333 & $\mathrm{~b}$ & C \\
\hline Harrow & 23 Sept. & Harrow & 21 Oct. & & & 75574 & $f$ & g & & 263 & g & \\
\hline Hoe & 9 Sept. & & & & & 87116 & $f$ & e & & 348 & $\mathrm{~b}$ & a \\
\hline Harrow & 16 Sept. & & & & & 101134 & & e & d & 321 & & $d c$ \\
\hline Harrow & 9 Sept. & & & & & 102498 & & e & d & 335 & b & a c \\
\hline Harrow & 23 Sep & & & & & 103759 & & $\mathrm{e}$ & $d$ & 302 & e & \\
\hline $\mathrm{Hoe}$ & 2 Sept. & & & & & 111968 & c & & $d$ & 351 & & a \\
\hline Harrow & 2 Sept. & & & & & 121633 & c & b & $d$ & 337 & b & a c \\
\hline Harrow & 1 April & & & & & 133555 & c & b & & 273 & $\mathrm{~g}$ & $f$ \\
\hline Harrow & 21 Oct. & & & & & 139342 & & $b$ & & 269 & $g$ & $f$ \\
\hline Harrow & 24 Nov. & & & & & 142724 & & $b$ & & 268 & $g$ & $f$ \\
\hline Control & & & & & & 188208 & & a & & 341 & $\mathrm{~b}$ & a \\
\hline
\end{tabular}

Means of a given column followed by the same letter are not significantly different at alpha $=0.05$

(Analysis of variance with scenario and repetition factors followed by least significant difference test). 
B. Winter Wheat

\begin{tabular}{|c|c|c|c|c|c|c|c|c|c|c|c|c|}
\hline \multicolumn{6}{|c|}{ Weeding scenarios } & \multirow{2}{*}{\multicolumn{3}{|c|}{$\begin{array}{l}\text { Seed production } \\
\left.\text {-(seeds } / \mathrm{m}^{2}\right)\end{array}$}} & \multirow{2}{*}{\multicolumn{4}{|c|}{$\begin{array}{l}\text { Seed bank before } \\
\left.\text { seed rain (seeds } / \mathrm{m}^{2}\right)\end{array}$}} \\
\hline \multicolumn{2}{|c|}{$1^{\text {st }}$ operation } & \multicolumn{2}{|c|}{$2^{\text {nd }}$ operation } & \multicolumn{2}{|c|}{$3^{\text {rd }}$ operation } & & & & & & & \\
\hline Harrow & & & & & & 13890 & $\mathrm{v}$ & & 551 & & $\mathrm{n}$ & \\
\hline Hoe & 30 Oct. & Hoe & 1 March & Hoe & 1 April & 22838 & v & $\mathrm{u}$ & 552 & & $\mathrm{n}$ & \\
\hline Hoe & 30 Oct. & Harrow & 1 March & Hoe & 1 April & 24978 & & u & 638 & & I & $\mathrm{m}$ \\
\hline Harrow & v 30 Oct. & Hoe & 1 March & Hoe & 1 April & 29504 & & $\mathrm{ut}$ & 804 & $\mathrm{~h}$ & $g$ & \\
\hline Hoe & 30 Oct. & Hoe & 1 March & Hoe & 1 April & 29885 & & $\mathrm{ut}$ & 553 & & $\mathrm{n}$ & \\
\hline Hoe & 30 Oct. & Hoe & 1 March & & & 30794 & $\mathrm{~s}$ & $\mathrm{ut}$ & 552 & & $\mathrm{n}$ & \\
\hline Harrow & v 30 Oct. & Harrow & 1 March & Hoe & 1 April & 31228 & $s$ & $\mathrm{ut}$ & 813 & $\mathrm{~h}$ & $g$ & \\
\hline Harrow & v 30 Oct. & Hoe & 1 March & Harrow & 1 April & 39043 & $\mathrm{~s}$ & $r t$ & 808 & $\mathrm{~h}$ & $g$ & \\
\hline Harrow & v 30 Oct. & Hoe & 1 April & & & 40708 & $s$ & $r$ & 686 & $\mathrm{k}$ & I & $\mathrm{m}$ \\
\hline Harrow & v 30 Oct. & Hoe & 20 Nov. & & & 43857 & & $r q$ & 673 & & I & $\mathrm{m}$ \\
\hline Harrow & v 30 Oct. & Hoe & 1 March & & & 45962 & $p$ & $r q$ & 733 & $\mathrm{k}$ & & j \\
\hline Harrow & v 30 Oct. & Hoe & 19 Feb. & & & 46470 & $p$ & $r q$ & 688 & $\mathrm{k}$ & I & \\
\hline Harrow & v 23 Oct. & Hoe & 20 Nov. & & & 46984 & $p$ & $r q$ & 644 & & I & $\mathrm{m}$ \\
\hline Harrow & v 30 Oct. & Harrow & 30 Nov. & Harrow & 1 April & 53826 & $p$ & $\circ q$ & 779 & $\mathrm{~h}$ & $\mathrm{i}$ & j \\
\hline Hoe & 30 Oct. & Harrow & 1 March & Harrow & 1 April & 56033 & $p$ & on & 639 & & I & $\mathrm{m}$ \\
\hline Harrow & v 30 Oct. & Harrow & 1 March & Harrow & 1 April & 63617 & $\mathrm{~m}$ & on & 817 & $\mathrm{~h}$ & $g$ & \\
\hline Hoe & 1 April & & & & & 65633 & $\mathrm{~m}$ & $n$ & 630 & & & $\mathrm{~m}$ \\
\hline Harrow & v 23 Oct. & Harrow & 20 Nov. & & & 65838 & $\mathrm{~m}$ & $\mathrm{In}$ & 646 & & I & $\mathrm{m}$ \\
\hline Harrow & v 30 Oct. & Harrow & 20 Nov. & & & $70974 \mathrm{~K}$ & $\mathrm{~m}$ & 1 & 736 & $\mathrm{k}$ & $\mathrm{i}$ & j \\
\hline Hoe & 20 March & & & & & $73820 \mathrm{~K}$ & $\mathrm{~m} \mathrm{j}$ & I & 571 & & $\mathrm{n}$ & \\
\hline Hoe & 19 Feb. & & & & & $75942 \mathrm{~K}$ & j & $\mathrm{I} \mathrm{i}$ & 568 & & $\mathrm{n}$ & \\
\hline Hoe & 5 March & & & & & $77546 \mathrm{~K}$ & $\mathrm{~h}$ & j i & 570 & & $\mathrm{n}$ & \\
\hline Harrow & v 30 Oct. & Harrow & 1 April & & & $80233 \mathrm{~K}$ & $\mathrm{~h} \mathrm{j}$ & g i & 790 & $\mathrm{~h}$ & i & \\
\hline Harrow & v 19 Feb. & Harrow & 10 March & Harrow & 1 April & 81576 & $\mathrm{~h} \mathrm{j}$ & $\mathrm{g} \mathrm{i}$ & 137 & & 0 & \\
\hline Harrow & v 30 Oct. & Harrow & 1 March & & & 84842 & $\mathrm{~h}$ & g i & 800 & $\mathrm{~h}$ & & \\
\hline Harrow & v 30 Oct. & Harrow & 19 Feb. & & & 87518 & $\mathrm{~h}$ & $g$ & 792 & $\mathrm{~h}$ & $\mathrm{i}$ & \\
\hline Hoe & 30 Oct. & & & & & 88707 & & g & 571 & & $\mathrm{n}$ & \\
\hline Harrow & v 23 Oct. & & & & & 106557 & & $\mathrm{f}$ & 922 & & e & \\
\hline Harrow & v 30 Oct. & & & & & 107033 & & $f$ & 1041 & & C & \\
\hline Hoe & 23 Oct. & & & & & 110901 & & $f$ & 570 & & $\mathrm{n}$ & \\
\hline Harrow & v 1 April & & & & & 133225 & & e & 1252 & & a & \\
\hline Harrow & v 20 March & & & & & 138801 & & e & 984 & & $d$ & \\
\hline Harrow & v 16 Oct. & & & & & 143144 & $d$ & e & 1121 & & $b$ & \\
\hline Harrow & v 5 March & & & & & 149216 & $d$ & C & 906 & $f$ & e & \\
\hline Harrow & v 19 Feb. & & & & & 153328 & $d$ & c & 857 & $f$ & g & \\
\hline Hoe & 16 Oct. & & & & & 153765 & & c & 572 & & $\mathrm{n}$ & \\
\hline Control & & & & & & 177374 & & $b$ & 1252 & & a & \\
\hline Hoe & 30 Oct. & Harrow & 1 April & & & 210222 & $\mathrm{a}$ & & 634 & & I & $\mathrm{m}$ \\
\hline
\end{tabular}

Means of a given column followed by the same letter are not significantly different at alpha $=0.05$ (Analysis of variance with scenario and repetition factors followed by least significant difference test). 
Table 4. Ranking of the tested mowing scenarios for controlling blackgrass seed bank left after three years of lucerne.

\begin{tabular}{lcc}
\hline Scenario (mowing dates) & Blackgrass seed bank (seeds $/ \mathrm{m}^{2}$ ) \\
\hline Triple mowing (mid-May, early July, mid-August) & 1266 & $\mathrm{~d}$ \\
Triple mowing (mid-May, mid-June, mid-July) & 1274 & $\mathrm{~d}$ \\
Double mowing (mid-May and mid-July) & 1819 & $\mathrm{~d}$ \\
Double mowing (mid-May and mid-June) & 1946 & $\mathrm{~d}$ \\
Triple mowing (late May, late June, late July) & 4292 & $\mathrm{~d}$ \\
Double mowing (mid-May and early June) & 7391 & $\mathrm{~d}$ \\
Single mowing (mid-June) & $25042 \mathrm{c}$ & $\mathrm{d}$ \\
Double mowing (mid-May and mid-August) & $66327 \mathrm{c}$ & $\mathrm{b}$ \\
Single mowing (mid-May) & $66509 \mathrm{c}$ & $\mathrm{b}$ \\
Single mowing (mid-July) & 108737 & $\mathrm{~b}$ \\
Control (no mowing) & 176453 & $\mathrm{a}$ \\
Single mowing (mid-August) & 178004 & $\mathrm{a}$
\end{tabular}

Means followed by the same letter are not significantly different at alpha $=0.05$ (least significant difference test). 
Table 5. Effect of weeding tool and date on weed survival and reproduction. Results of linear regression [ 9 ]

A. Oilseed rape

\begin{tabular}{|c|c|c|c|c|c|c|c|}
\hline \multirow{3}{*}{ Weed stage } & & \multicolumn{4}{|c|}{ Factor } & \multirow{3}{*}{ Repetition } & \multirow[t]{3}{*}{$\mathrm{R}^{2}$} \\
\hline & & \multicolumn{2}{|c|}{ Weeding tool } & \multicolumn{2}{|c|}{ Weeding date } & & \\
\hline & & $\begin{array}{l}\text { Hoe } \\
\text { toolhoe }\end{array}$ & $\begin{array}{l}\text { Harrow } \\
\text { tool harrow }\end{array}$ & $\begin{array}{l}\text { Hoe } \\
a+b_{\text {hoe }}\end{array}$ & $\begin{array}{l}\text { Harrow } \\
a+b_{\text {harrw }}\end{array}$ & & \\
\hline \multirow[t]{2}{*}{$\begin{array}{l}\text { Plant survival after weeding } \\
\text { (plants/plants) }\end{array}$} & $\begin{array}{l}\text { Regression } \\
\text { coefficient }\end{array}$ & 0.13 & -0.13 & -0.12 & 0.022 & ns & \\
\hline & Partial $R^{2}$ & 0.12 & & 0.78 & & 0.00 & 0.90 \\
\hline \multirow[t]{2}{*}{$\begin{array}{l}\text { Mature weeds at crop } \\
\text { harvest (plants } / \mathrm{m}^{2} \text { ) }\end{array}$} & $\begin{array}{l}\text { Regression } \\
\text { coefficient }\end{array}$ & 0.33 & -0.33 & -0.23 & 0.054 & $\mathrm{nl}$ & \\
\hline & Partial $R^{2}$ & 0.09 & & 0.29 & & 0.53 & 0.91 \\
\hline \multirow[t]{2}{*}{ Seed production (seeds $/ \mathrm{m}^{2}$ ) } & $\begin{array}{l}\text { Regression } \\
\text { coefficient }\end{array}$ & 0.27 & -027 & -025. & 0.066 & $\mathrm{nl}$ & \\
\hline & Partial $R^{2}$ & 0.025 & & 0.17 & & 0.71 & 0.90 \\
\hline \multirow[t]{2}{*}{$\begin{array}{l}\text { Seed bank before seed rain } \\
\left(\text { seeds } / \mathrm{m}^{2}\right)\end{array}$} & $\begin{array}{l}\text { Regression } \\
\text { coefficient }\end{array}$ & 0.013 & -0.013 & -0.90 & & $\mathrm{nl}$ & \\
\hline & Partial $R^{2}$ & 0.003 & & 0.14 & & 0.79 & 0.93 \\
\hline
\end{tabular}

B. Winter wheat

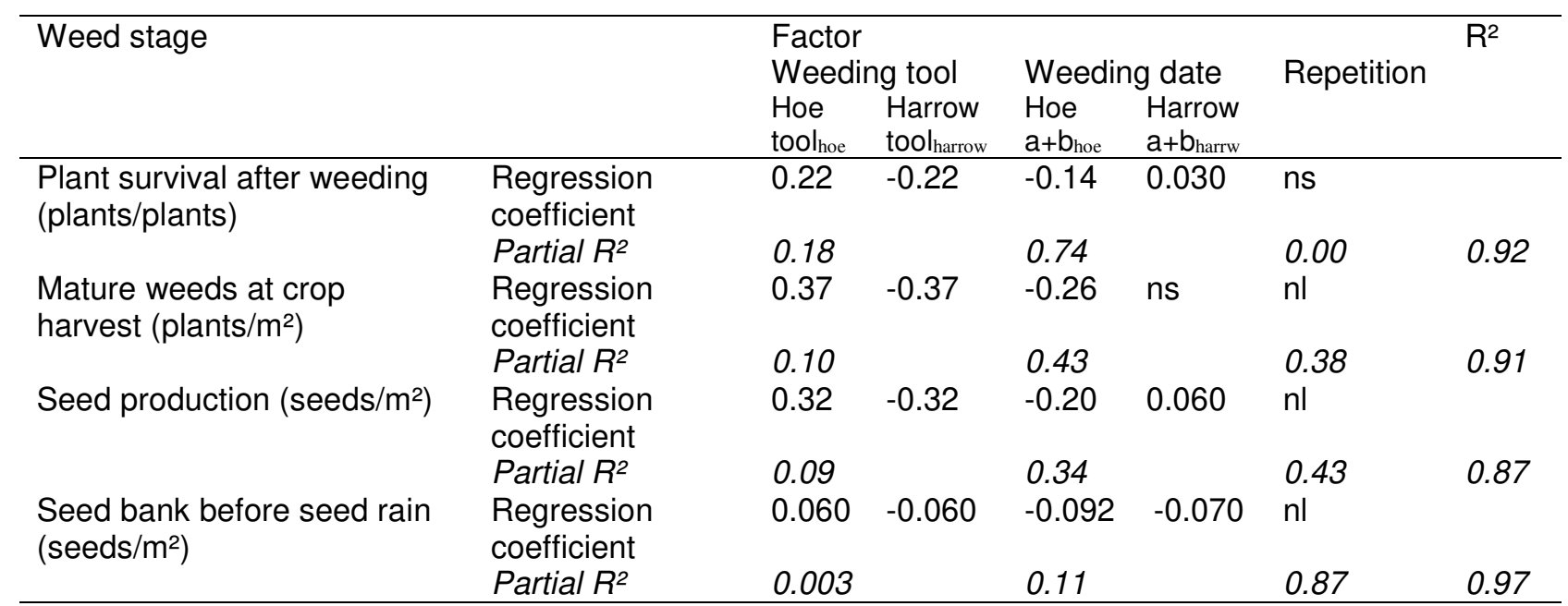

All density variables and weeding dates were $\log _{\mathrm{e}}$-transformed prior to analysis. The tested regression was $\log _{\mathrm{e}}\left(\right.$ ALOMYSYS output $\left.t_{\mathrm{j}}\right)=$ constant + tool $_{\mathrm{i}}+$ repetition $_{\mathrm{j}}+a \cdot \log _{\mathrm{e}}($ weeding date $)+b_{\mathrm{i}} \cdot \log _{\mathrm{e}}$ (weeding date $)+$ error $_{\mathrm{ij}}$, with $\mathrm{i}$ being either hoe or harrow and the repetition indicator $\mathrm{j} \in\{1, \ldots, 10\}$.

Working depth was $2 \mathrm{~cm}$, working speed $2.5 \mathrm{~m} / \mathrm{s}$ and hoed area was 0.7 .

ns: not significative at alpha $=0.05$

$\mathrm{nl}$ : regression coefficients not listed 
Table 6. Effect of weeding depth, speed and area on blackgrass infestation in OSR simulated by ALOMYSYS.

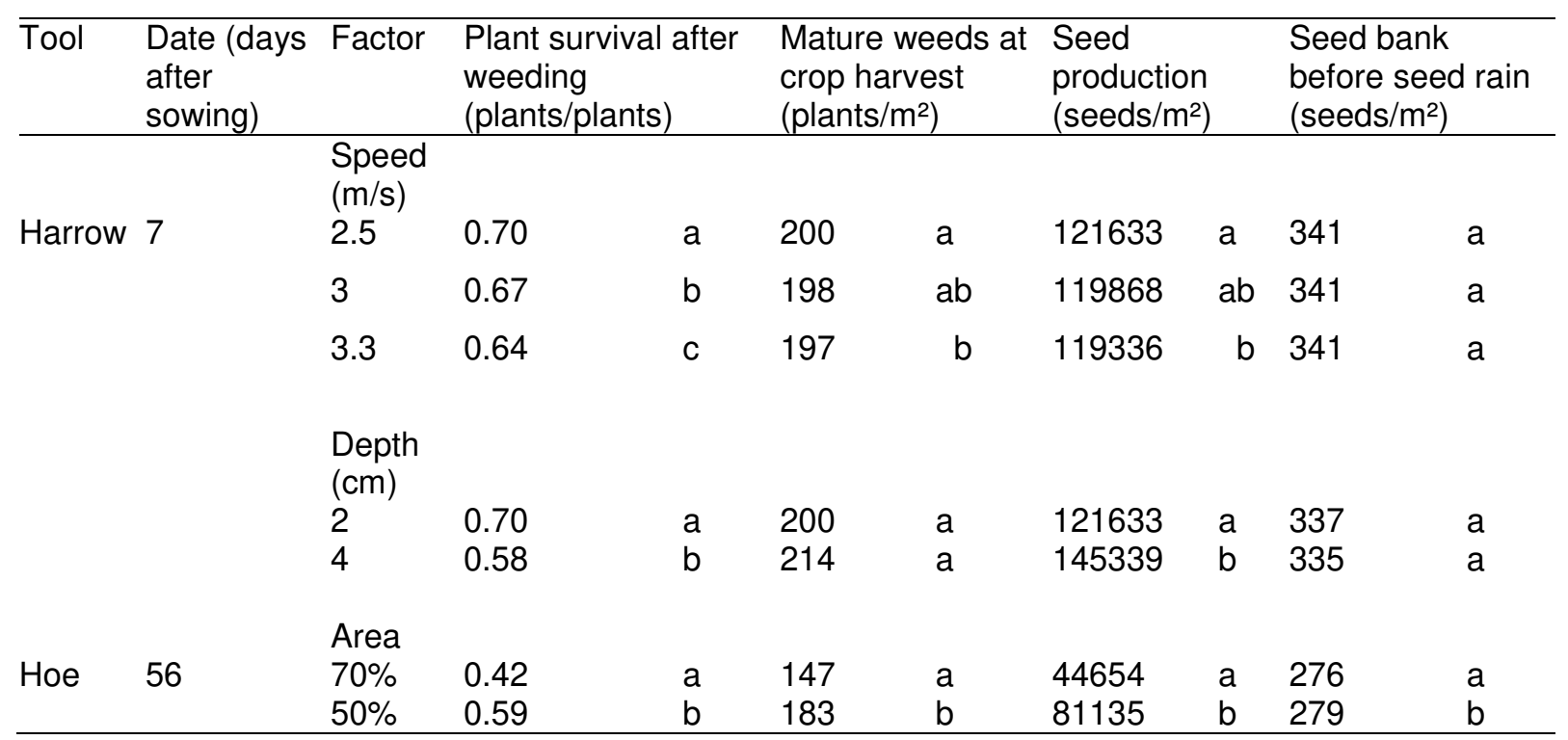

Except when otherwise indicated, working depth was $2 \mathrm{~cm}$, working speed $2.5 \mathrm{~m} / \mathrm{s}$ and hoed area was 0.7. Means of a given column and a specific test (speed, depth or area) followed by the same letter are not significantly different at alpha $=0.05$ (Analysis of variance with scenario and repetition factors followed by least significant difference test) 
Table 7 Long-term evaluation of scenarios with multi-year simulations using ALOMYSYS

\begin{tabular}{|c|c|c|c|c|c|c|c|c|c|c|c|}
\hline \multirow{3}{*}{\multicolumn{2}{|c|}{ Scenario }} & \multicolumn{4}{|c|}{$\begin{array}{l}\text { Short-term infestation } \\
\text { (mean over rotation, years 1-3) }\end{array}$} & \multicolumn{3}{|c|}{$\begin{array}{l}\text { Medium-term infestation } \\
\text { (mean over rotation, years 13-15) }\end{array}$} & \multicolumn{3}{|c|}{$\begin{array}{l}\text { Long-term dynamics } \\
\text { (Spearman correlation } \\
\text { coefficient, years 13-26) }\end{array}$} \\
\hline & & \multicolumn{2}{|c|}{$\begin{array}{l}\text { Mature } \\
\text { weeds } / \mathrm{m}^{2}\end{array}$} & \multicolumn{2}{|c|}{$\begin{array}{l}\text { Repetitions where } \\
\text { scenario }\end{array}$} & \multicolumn{2}{|c|}{$\begin{array}{l}\text { Mature } \\
\text { weeds } / \mathrm{m}^{2}\end{array}$} & \multirow[t]{2}{*}{$\begin{array}{l}\text { Repetitions where } \\
\text { scenario >> } \\
\text { reference }^{2}\end{array}$} & \multirow[t]{2}{*}{$\begin{array}{l}\text { Correlation } \\
(\text { mean })^{3}\end{array}$} & \multicolumn{2}{|c|}{$\begin{array}{l}\text { Repetitions } \\
\text { where } \\
\text { scenario }\end{array}$} \\
\hline & & Mean $^{1}$ & SE & reference $^{2}$ & $\begin{array}{l}<< \\
\text { reference }\end{array}$ & Mean $^{1}$ & SE & & & $>>0^{4}$ & $<<0^{4}$ \\
\hline $\mathrm{R}$ & Herbicide-based reference system & $18 \mathrm{c}$ & 5 & & & $<0.1 \mathrm{a}$ & $<0.1$ & & $-0.145 \mathrm{~ns}$ & $0 \%$ & $10 \%$ \\
\hline M1 & $\begin{array}{l}\text { Triple hoeing in OSR, sextuple harrowing in } \\
\text { cereals }\end{array}$ & $33 f$ & 5 & $60 \%$ & $0 \%$ & $490 \mathrm{~d}$ & 48 & $100 \%$ & $-0.062 \mathrm{~ns}$ & $10 \%$ & $10 \%$ \\
\hline M2 & Triple hoeing in all crops & $42 \mathrm{~g}$ & 8 & $60 \%$ & $0 \%$ & 568 e & 52 & $100 \%$ & $-0.059 \mathrm{~ns}$ & $0 \%$ & $10 \%$ \\
\hline L1 & $\begin{array}{l}\text { M1 + 3-year no-till lucerne with optimal } \\
\text { cutting (OSR/WW/WB/3L) }\end{array}$ & $27 \mathrm{e}$ & 4 & $10 \%$ & $10 \%$ & $36 \mathrm{~b}$ & 8 & $0 \%$ & $-0.131 \mathrm{~ns}$ & $0 \%$ & $10 \%$ \\
\hline L2 & $\begin{array}{l}\text { M1 + 6-year no-till lucerne with optimal } \\
\text { cutting (OSR/WW/WB/OSR/WW/WB/6L) }\end{array}$ & $32 \mathrm{f}$ & 5 & $30 \%$ & $10 \%$ & $100 \mathrm{c}$ & 13 & $30 \%$ & -0.251 & $0 \%$ & $20 \%$ \\
\hline L3 & L1 with tillage before lucerne & $27 \mathrm{e}$ & 4 & $10 \%$ & $10 \%$ & $2 \mathrm{a}$ & 1 & $0 \%$ & $-0.010 \mathrm{~ns}$ & $30 \%$ & $20 \%$ \\
\hline P1 & $\begin{array}{l}\text { L3 with chisel replaced by mouldboard } \\
\text { ploughing before each annual crop }\end{array}$ & $13 \mathrm{a}$ & 2 & $0 \%$ & $20 \%$ & $0.2 \mathrm{a}$ & 0.1 & $0 \%$ & $-0.050 \mathrm{~ns}$ & $20 \%$ & $20 \%$ \\
\hline P2 & $\begin{array}{l}\text { L3 with chisel replaced by mouldboard } \\
\text { ploughing before OSR only }\end{array}$ & $27 \mathrm{e}$ & 4 & $10 \%$ & $10 \%$ & $1 \mathrm{a}$ & 1 & $0 \%$ & $0.007 \mathrm{~ns}$ & $10 \%$ & $0 \%$ \\
\hline P3 & $\begin{array}{l}\text { L3 with chisel replaced by mouldboard } \\
\text { ploughing before WW only }\end{array}$ & $16 b$ & 2 & $0 \%$ & $20 \%$ & $1 \mathrm{a}$ & 1 & $0 \%$ & $-0.084 \mathrm{~ns}$ & $0 \%$ & $0 \%$ \\
\hline P4 & $\begin{array}{l}\text { L3 with chisel replaced by mouldboard } \\
\text { ploughing before WB only }\end{array}$ & $22 d$ & 3 & $0 \%$ & $10 \%$ & $0.4 \mathrm{a}$ & 0.2 & $0 \%$ & -0.0002 ns & $10 \%$ & $10 \%$ \\
\hline
\end{tabular}

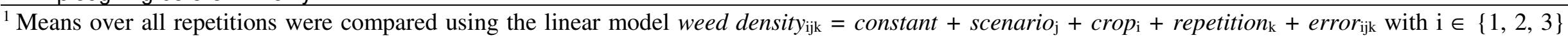
(initial infestation) or $\{13,14,15\}$ (medium-term infestation) and means followed by the same letter were not significantly different at alpha $=0.05$.

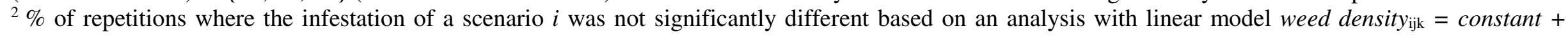
scenario $_{\mathrm{j}}+$ crop $_{\mathrm{i}}+$ error $_{\mathrm{ijk}}$ for each repetition $k \in\{1, \ldots 10\}$.

${ }^{3}$ Spearman correlation coefficient calculated with PROC CORR of SAS between weed density and year for years 13 to 27.

$4 \%$ of repetitions where the Spearman correlation coefficient calculated between weed density and year for each repetition for years 13 to 27 was significantly different from zero at alpha $=0.05$. ns indicates that this mean correlation is not significantly different from zero at alpha $=0.05$. 

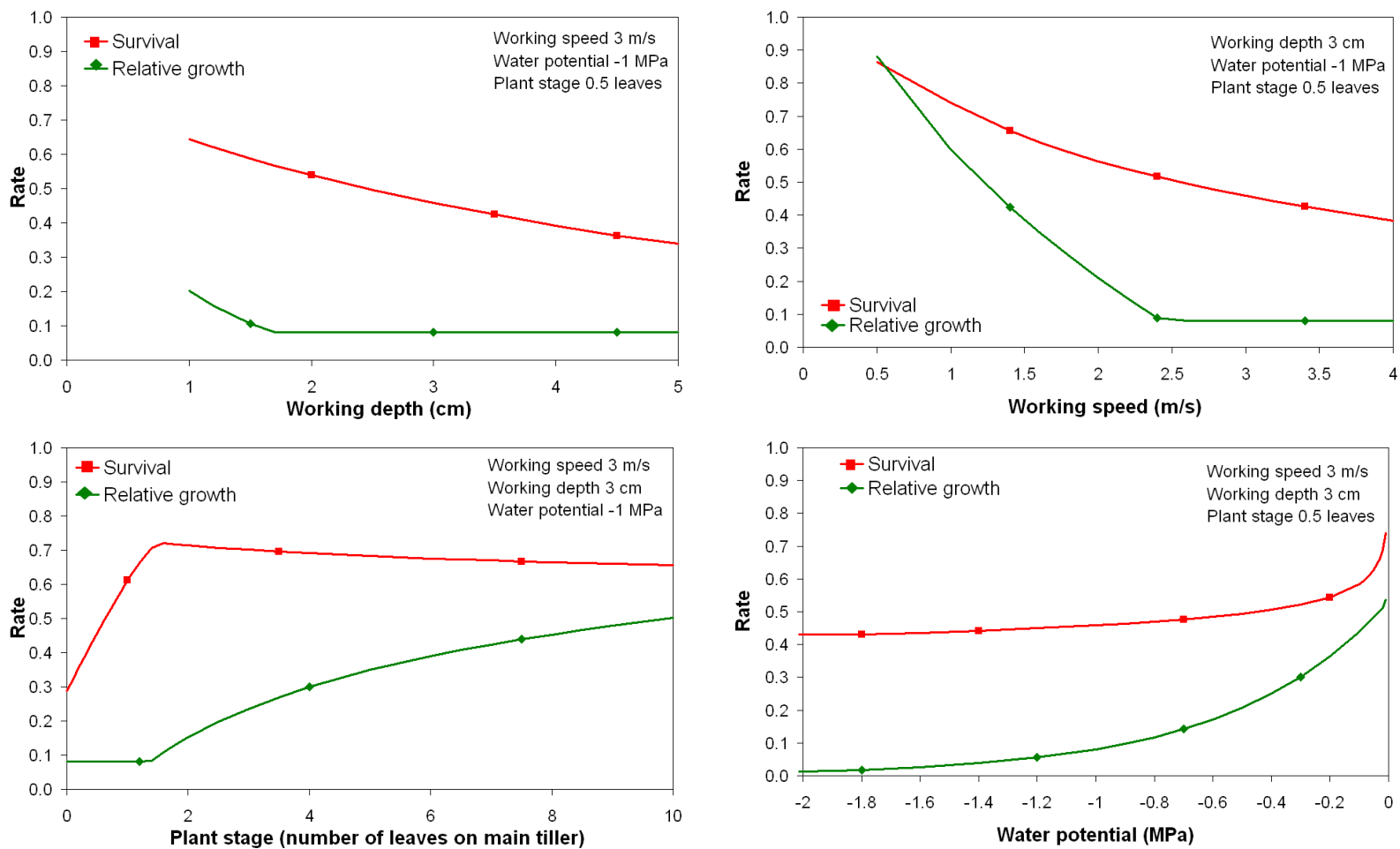

Figure 1. Sensitivity analysis of plant survival and post-harrowing plant growth to harrowing speed and depth as well as soil moisture and blackgrass stage 

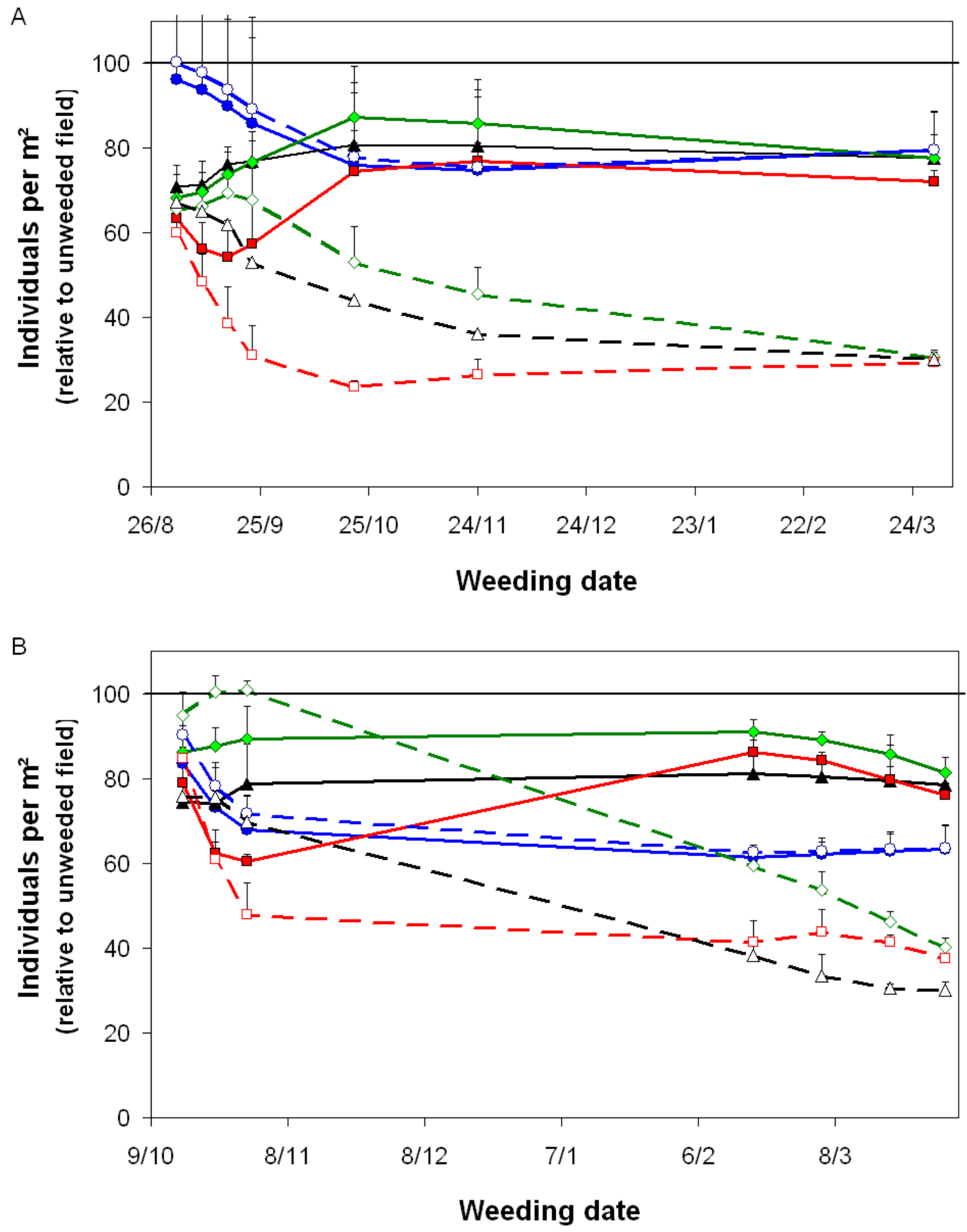

Figure 2. Effect of weeding tool (harrow: continuous line, hoe: broken line) and date on relative variations in blackgrass densities $(\bullet$ : seed bank before seed rain; $\mathbf{\Delta}$ : plant survival after weeding; mature plants at harvest; $\mathbf{\square}$ : seed production) in oilseed rape (A) and winter wheat (B) simulated with ALOMYSYS $(100 \%$ = unweeded control). Mean and standard-deviation of ten repetitions simulated with randomly chosen weather scenarios from Dijon (1986-2004). Values above 100 indicate an increase in blackgrass, values below a decrease relative to the unweeded treatment. 
Alternative version of Figure 2
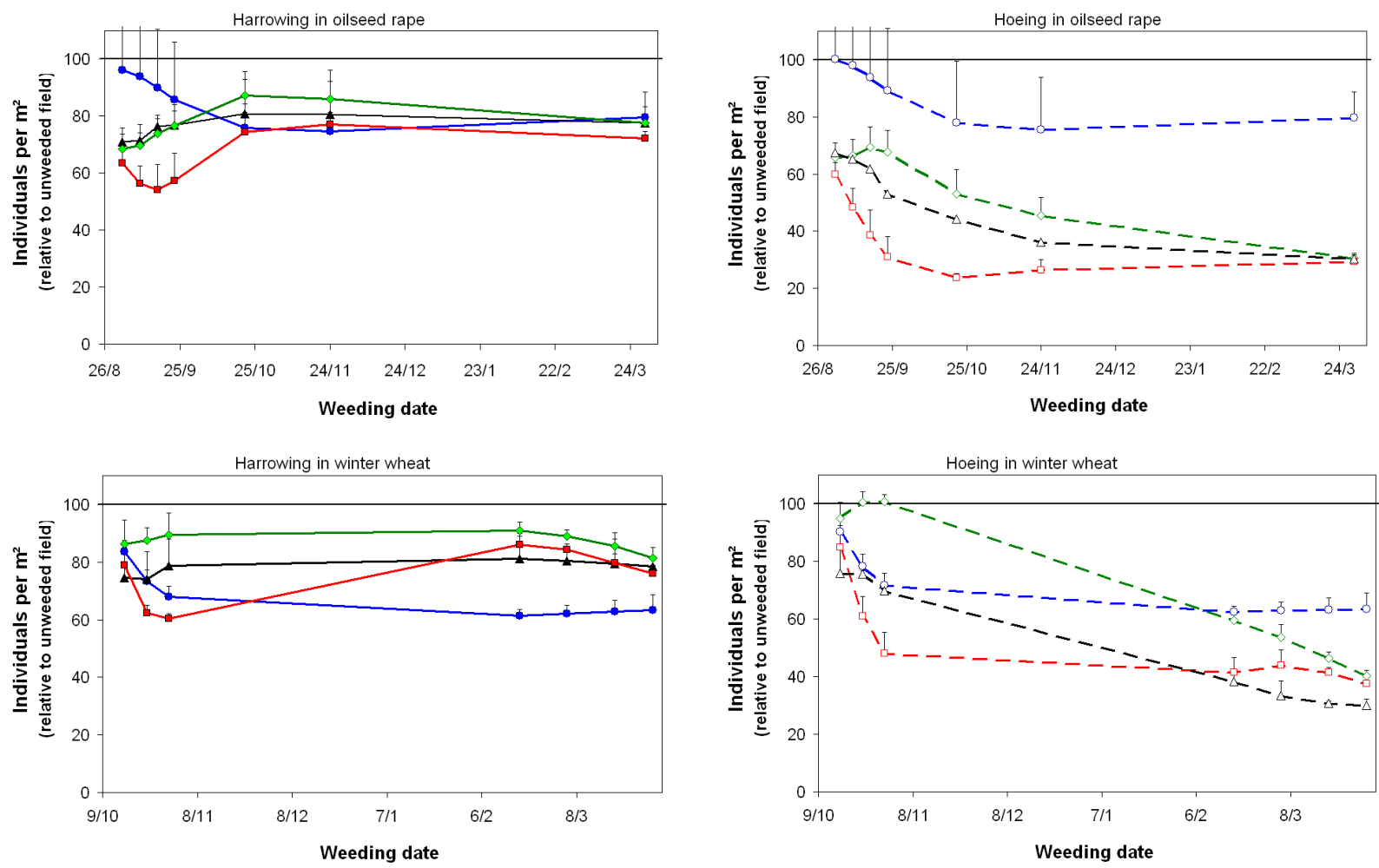

Figure 3. Effect of weeding tool and date on relative variations in blackgrass densities ( $\bullet$ : seed bank before seed rain; $\mathbf{\Lambda}$ : plant survival after weeding; mature plants at harvest; $\mathbf{\square}$ : seed production) in two winter crops simulated with ALOMYSYS (100\% = unweeded control). Mean and standarddeviation of ten repetitions simulated with randomly chosen weather scenarios from Dijon (19862004). Values above 100 indicate an increase in blackgrass, values below a decrease relative to the unweeded treatment. 


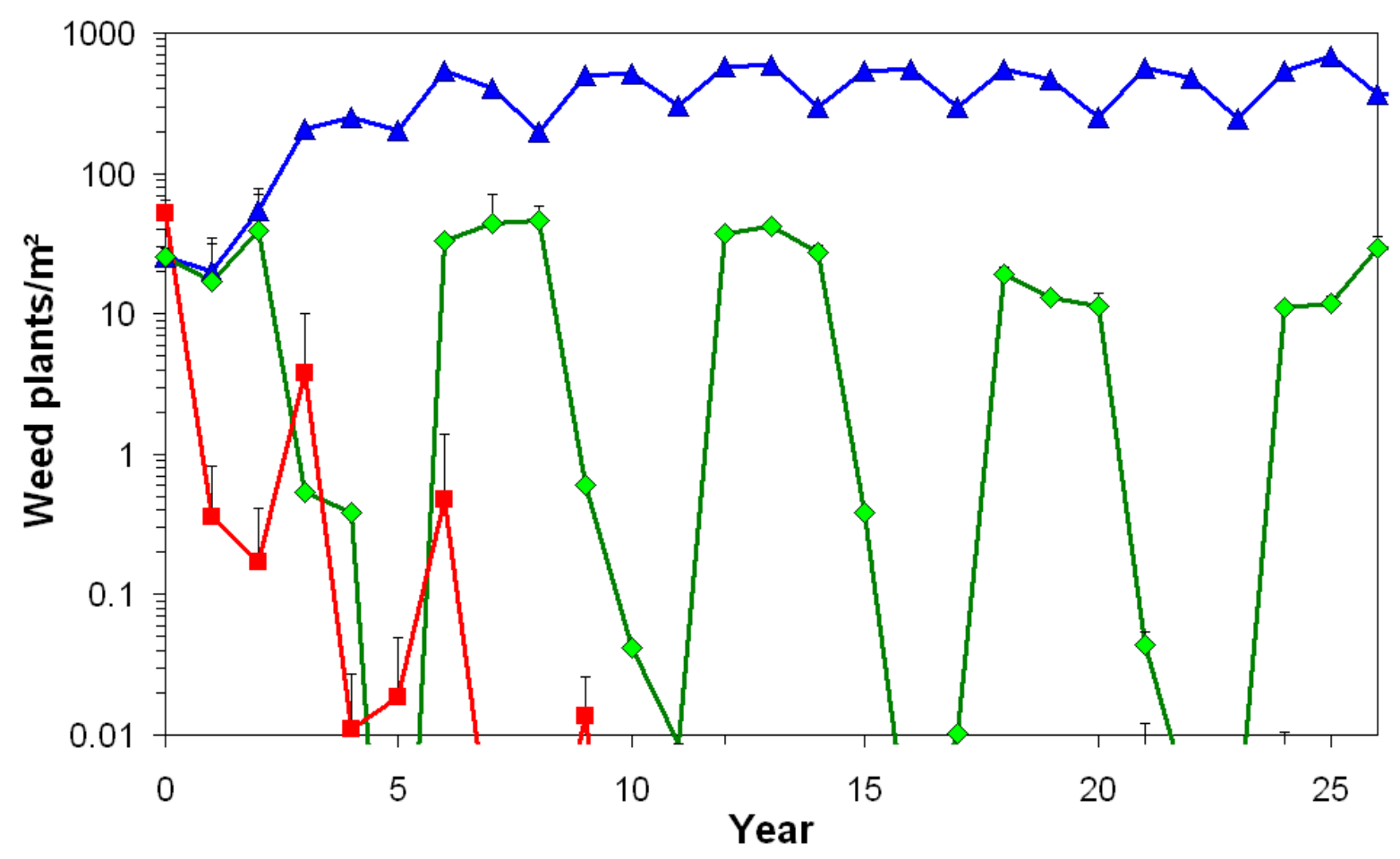

Figure 4. Mature weed densities at crop harvest (mean and standard-error from ten repetitions with randomly chosen weather series) simulated with ALOMYSYS for three scenarios: OSR/WW/WB with herbicides (scenario R, squares), the same rotation with optimal mechanical weeding (scenario $\mathrm{M} 1$, triangles) and a six-year rotation with OSR/WW/WB followed by three-year lucerne mown thrice every year (scenario L1, diamonds). The letters on top show the crops $(\mathrm{O}=$ oilseed rape, $\mathrm{W}=$ winter wheat, $\mathrm{B}=$ barley, $\mathrm{L}=$ lucerne). 